University of South Florida

DIGITAL COMMONS

Digital Commons @ University of

@ UNIVERSITY OF SOUTH FLORIDA

South Florida

6-2021

\title{
A Machine Learning Approach to Estimate Surface Chlorophyll a Concentrations in Global Oceans From Satellite Measurements
}

\author{
Chuanmin $\mathrm{Hu}$ \\ University of South Florida, huc@usf.edu \\ Lian Feng \\ University of Science and Technology \\ Qi Guan \\ University of Science and Technology, University of Copenhagen
}

Follow this and additional works at: https://digitalcommons.usf.edu/msc_facpub

Part of the Life Sciences Commons

\section{Scholar Commons Citation}

Hu, Chuanmin; Feng, Lian; and Guan, Qi, "A Machine Learning Approach to Estimate Surface Chlorophyll a Concentrations in Global Oceans From Satellite Measurements" (2021). Marine Science Faculty Publications. 2041.

https://digitalcommons.usf.edu/msc_facpub/2041

This Article is brought to you for free and open access by the College of Marine Science at Digital Commons @ University of South Florida. It has been accepted for inclusion in Marine Science Faculty Publications by an authorized administrator of Digital Commons @ University of South Florida. For more information, please contact digitalcommons@usf.edu. 


\title{
A Machine Learning Approach to Estimate Surface Chlorophyll $a$ Concentrations in Global Oceans From Satellite Measurements
}

\author{
Chuanmin $\mathrm{Hu}^{(\mathbb{1}}$, Lian Feng ${ }^{(\mathbb{D}}$, and Qi Guan ${ }^{(\mathbb{D}}$
}

\begin{abstract}
Various approaches have been proposed to estimate surface ocean chlorophyll $a$ concentrations $\left(\mathrm{Chl}, \mathrm{mg} \mathrm{m}^{-3}\right.$ ) from spectral reflectance measured either in the field or from space, each with its own strengths and limitations. Here, we develop a machine learning approach to reduce the impact of spectral noise and improve algorithm performance at the global scale for multiple satellite sensors. Among several candidates, the support vector regression (SVR) approach was found to yield the best algorithm performance as gauged by several statistical measures against field-measured Chl. While statistically the performance of the SVR is slightly worse than the empirical color index (CI) algorithm proposed in $\mathrm{Hu}$ et al. (2012) for Chl $<0.25 \mathrm{mg} \mathrm{m}^{-3}$, its applicability to global waters is much extended, from the CIs $0.01-0.25 \mathrm{mg} \mathrm{m}^{-3}$ (about $75 \%$ of the global oceans) to its $0.01-1 \mathrm{mg}^{-3}$ [about $96 \%$ of global oceans according to Sea-viewing Wide Field-of-view Sensor (SeaWiFS) statistics]. Within this range, not only does the SVR show much improved performance over the traditional band-ratio OCx approaches, but the SVR leads to much reduced image noise and much improved cross-sensor consistency between SeaWiFS and Moderate Resolution Spectroradiometer (MODIS)/Aqua and between MODIS/Aqua and Visible Infrared Imaging Radiometer Suite (VIIRS). Furthermore, compared with the hybrid Ocean CI (OCI) algorithm currently used by the U.S. NASA as the default algorithm for all mainstream ocean color sensors, the SVR avoids the need to merge two different algorithms for intermediate $\mathrm{Chl}$ (band subtraction for $\mathrm{CI}$ and band ratio for $\mathrm{OC} x$ ), thus may serve as an alternative approach for global data processing.
\end{abstract}

Index Terms-Algorithm, chlorophyll $a$, empirical, machine learning, Moderate Resolution Spectroradiometer (MODIS), ocean color, remote sensing, Sea-viewing Wide Field-of-view Sensor (SeaWiFS), support vector regression (SVR), Visible Infrared Imaging Radiometer Suite (VIIRS).

Manuscript received November 10, 2019; revised June 14, 2020; accepted July 18, 2020. Date of publication September 15, 2020; date of current version May 21, 2021. This work was supported in part by the Joint Polar Satellite System Funding for the National Oceanic and Atmospheric Administration (NOAA) Ocean Color Calibration and Validation (Cal/Val) under Project NA15OAR4320064. (Corresponding author: Chuanmin Hu.)

Chuanmin $\mathrm{Hu}$ is with the College of Marine Science, University of South Florida, St. Petersburg Campus, St. Petersburg, FL 33701 USA (e-mail: huc@usf.edu).

Lian Feng is with the School of Environmental Science and Engineering, Southern University of Science and Technology, Shenzhen 518055, China.

Qi Guan is with the School of Environmental Science and Engineering, Southern University of Science and Technology, Shenzhen 518055, China, and also with the Department of Geoscience and Natural Resource Management, University of Copenhagen, 1165 Copenhagen, Denmark.

This article has supplementary downloadable material available at https://ieeexplore.ieee.org, provided by the authors.

Color versions of one or more of the figures in this article are available online at https://ieeexplore.ieee.org.

Digital Object Identifier 10.1109/TGRS.2020.3016473

\section{INTRODUCTION}

$\mathbf{O}$ $\mathrm{NE}$ of the primary ocean color data products from satellite measurements is the surface ocean chlorophyll $a$ concentration $\left(\mathrm{Chl}, \mathrm{mg} \mathrm{m}^{-3}\right)$. This is usually through two steps (see review by $\mathrm{Hu}$ and Campbell [1]): atmospheric correction to derive the spectral surface remote-sensing reflectance $\left(R_{\mathrm{rs}}(\lambda), \mathrm{sr}^{-1}\right)$ from the calibrated at-sensor spectral radiance $\left(L_{\mathrm{t}}(\lambda), \mathrm{mW} \mathrm{cm}{ }^{-2} \mu \mathrm{m}^{-1} \mathrm{sr}^{-1}\right)$ [2]-[4], and bio-optical inversion to estimate $\mathrm{Chl}$ from $R_{\mathrm{rs}}(\lambda)$ using an algorithm established from field measured $\mathrm{Chl}$ and $R_{\mathrm{rs}}(\lambda)$. The latter is the subject of this study.

There are two general approaches to develop algorithms to estimate Chl from $R_{\mathrm{rs}}(\lambda)$ : empirical and semianalytical [1]. The former is based on the principle that, for most waters, $R_{\mathrm{rs}}$ in the blue decreases with increasing Chl while $R_{\mathrm{rs}}$ in the green is more stable, leading to algorithms to use $R_{\mathrm{rs}}$ band ratios (blue/green) or band subtractions (blue-green or blue-green-red) to estimate Chl [5]-[15]. Such empirical Chl algorithms do not distinguish $\mathrm{Chl}$ from other water constituents such as colored dissolved organic matter (CDOM) or suspended nonliving particles, and in waters where they do not covary the algorithms may lead to large uncertainties [16]-[18]. In contrast, semianalytical algorithms estimate Chl (or phytoplankton pigment absorption) and other water constituents at the same time, based on the spectral optical properties of these water constituents (e.g., [19]-[27]).

While both empirical and semianalytical approaches have their strengths and limitations, because empirical algorithms are simple to design and implement and generally more tolerant to spectral noise, they have been used widely, especially for regional studies where algorithm coefficients can be tuned with field data (e.g., [28]-[30]). For global applications, the blue/green band ratio algorithms (hereafter referred to $\mathrm{OC} x$ where $x$ represents the number of spectral bands used in the algorithm [12], [31]) have been used by the U.S. NASA since the 1980s to process ocean color data collected by the Coastal Zone Color Scanner (1978-1986), Sea-viewing Wide Fieldof-view Sensor (SeaWiFS, 1997-2010), Moderate Resolution Spectroradiometer (MODIS, 2000-present on Terra and 2002present on Aqua), Medium Resolution Imaging Spectrometer (MERIS, 2002-2012), Visible Infrared Imaging Radiometer Suite (VIIRS, 2012-present), among others. Recently, the OCx algorithms have been updated to incorporate the advantage of the blue-green-red color index (CI) algorithm for low-Chl 
TABLE I

Chl RANGES (IN $\mathrm{mg} \mathrm{m}^{-3}$ ) OF THE DATA From THE NOMAD2 AND SEABASS Data SETS Used for Algorithm DeVelopment and VAlidation, Respectively

\begin{tabular}{ccccccc}
\hline & Min & Max & Mean & Median & STD & \# of points \\
\hline NOMAD2 & 0.03 & 77.86 & 2.89 & 0.90 & 6.29 & 638 \\
SeaBASS for SeaWiFS & 0.01 & 32.18 & 1.30 & 0.57 & 2.32 & 1145 \\
SeaBASS for Aqua & 0.03 & 29.00 & 1.49 & 0.72 & 2.71 & 331 \\
\hline
\end{tabular}

waters [14], leading to a hybrid Ocean CI (OCI) algorithm as the default algorithm for all ocean color sensors [13], [14].

The success of the global empirical algorithms is mainly due to the fact that, for most waters, relative to $R_{\mathrm{rs}}$ in the green, $R_{\mathrm{rs}}$ in the blue decreases with increasing Chl. When other water constituents such as CDOM or suspended sediments overwhelm phytoplankton to dominate the $R_{\mathrm{rs}}$ changes, for example in CDOM-rich or sediment-rich coastal waters, the OC $x$ or OCI algorithms often fail. In such cases, in addition to using semianalytical algorithms to separate the water constituents explicitly, machine learning empirical approaches such as neural networks (e.g., [32]-[37]) may be developed for regional applications. Indeed, numerous articles have used machine learning approaches to achieve improved retrievals of ocean color variables over other empirical algorithms that have explicit functional forms. Several common machine learning approaches, including multilayer perceptron (MLP), artificial neural network (ANN), and support vector machine (SVM), were used to derive Chl concentrations for Cases I and II waters on global and regional scales [32], [34], [38]-[42]. Similar approaches also performed well for retrieving diffuse attenuation coefficient $\left(K_{\mathrm{d}}\right)$ and inherent optical properties (IOPs) for both coastal and open oceanic waters [43]-[45]. Although the governing equations are not explicit in these approaches, the variable dependences of $R_{\mathrm{rs}}(\lambda)$ on the different water constituents are taken care of by the internal functions of machine learning. As long as the training data set covers sufficient data range and variable proportions of the water constituents, these approaches appear to work well. However, machine learning approaches on global $\mathrm{Chl}$ retrievals have not been attempted, or at least have not been reported in the literature.

Recognizing the strengths and limitations of the three types of empirical approaches [OC $x, \mathrm{CI}$, machine learning] and the lack of a global $\mathrm{Chl}$ algorithm based on machine learning, the objective of this article is to develop an optimal machine learning algorithm to estimate $\mathrm{Chl}$ for most waters in global oceans. Currently, although OCI is being used by NASA as the default algorithm for multiple sensors because of its tolerance to $R_{\mathrm{rs}}(\lambda)$ errors for low-Chl waters and because of its improved cross-sensor consistency over the OCx algorithms, the algorithm switch from low- to higher-Chl waters leads to the question of whether there exists a machine learning approach to combine the advantages of the CI algorithm [for its tolerance to spectrally related $R_{\mathrm{rs}}(\lambda)$ noise or errors], the OC $x$ algorithm (for its simple blue/green principle), and the computer intelligence (for its implicit treatment of variable relationships among the water constituents). This article is to explore the various machine learning approaches, from which an optimal one is selected for global applications.

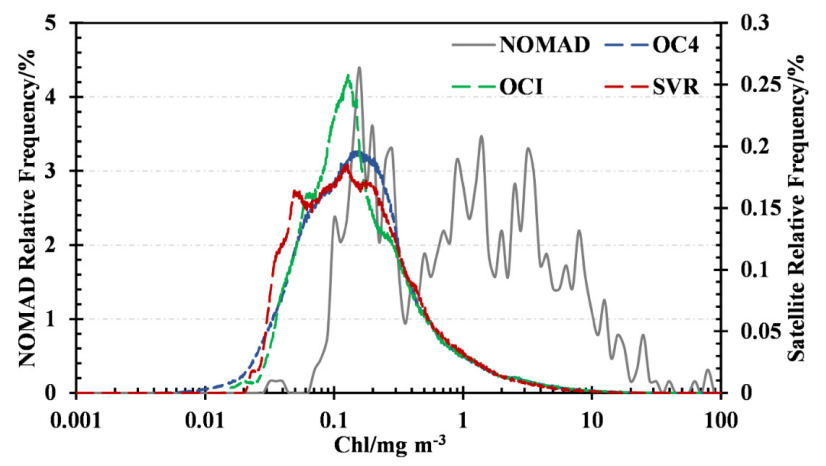

Fig. 1. Relative frequency distributions of $\mathrm{Chl}$ for NOMAD data set (training data set for SVR algorithm in this study) and global SeaWiFS images derived from OC4, OCI, and SVR in January and June 2010.

\section{DATA AND METhODS}

\section{A. Field Data for Algorithm Development: NASA Bio-Optical Marine Algorithm Data Set Version 2}

For consistency, the same data set used in previous algorithm developments, namely the NASA bio-Optical Marine Algorithm Data set (NOMAD) (version 2) containing field measured $R_{\mathrm{rs}}(\lambda)$ and Chl data [46] (Table I and Fig. 1), was used for algorithm development. These $R_{\mathrm{rs}}(\lambda)$ and Chl data were collected by many research groups around the world, and they covered large dynamic ranges and variable oceanic environments, thus forming appropriate data pairs for algorithm development. Most Chl data were determined fluorometrically from water samples, and $R_{\mathrm{rs}}(\lambda)$ data have been collected in the field following NASA-recommended Ocean Optics protocols.

\section{B. Algorithm Development}

There are different types of machine learning, which have all been considered or tested.

First, deep learning was considered but not tested because 1) only 638 data pairs (i.e., $R_{\mathrm{rs}}$ and $\mathrm{Chl}$ ) from NOMAD could be found and 2) only six bands could be used if a sensor-specific algorithm were to be applied to both SeaWiFS and MODISA (MODIS/Aqua). The limited data volume makes it impractical to involve deep learning.

Second, of other machine learning approaches, several popular approaches have been tested with various $R_{\mathrm{rs}}$ input forms (see below). These include Gaussian Process (GP), Random Forest (RF), MLP, and support vector regression (SVR). Through extensive tests, it was found that SVR yielded the best algorithm performance in terms of uncertainty statistics. For reference, results from these approaches are presented in Supplementary Table S1. For illustration purpose, 


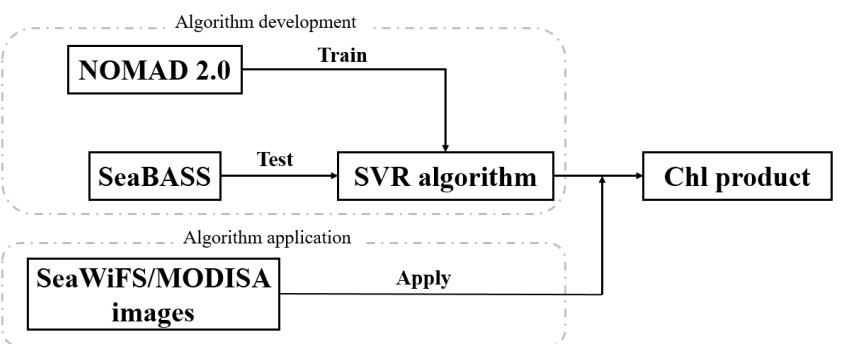

Fig. 2. Flowchart to show the development of the SVR algorithm and its application to satellite data to derive the Chl data product. For brevity, VIIRS is not included in the flowchart, but was used in the application.

Fig. 2 shows a flowchart of how the SVR algorithm is developed from the NOMAD data, applied to satellite data, and then evaluated within SeaWiFS Bio-optical Archive and Storage System (SeaBASS) data (see Section II-C).

Finally, the optimal way on how to use $R_{\mathrm{rS}}(\lambda)$ as the SVR model inputs was determined from trial and error. Originally, $R_{\mathrm{rs}}(\lambda)$ values at 443,490, 555, and $670 \mathrm{~nm}$ were as the inputs, yet the performance was not satisfactory (Supplementary Table S2). Then, various forms of $R_{\mathrm{rS}}(\lambda)$ band combinations were tried, including band ratios and band differences (e.g., CI defined in [14]). After extensive tests, it was determined that the following $R_{\mathrm{rs}}$ combinations would yield the best algorithm performance, therefore used to train the SVR algorithm used in this study to derive global Chl maps

$$
\begin{aligned}
& \left(R_{\mathrm{rs}}(490)-R_{\mathrm{rs}}(443)\right) /(490-443) \\
& \left(R_{\mathrm{rs}}(555)-R_{\mathrm{rs}}(510)\right) /(555-510) \\
& R_{\mathrm{rs}}(555)-\left(R_{\mathrm{rs}}(670)-R_{\mathrm{rs}}(443)\right) *(555-443) /(670-443) \\
& R_{\mathrm{rs}}(555)-\left(R_{\mathrm{rs}}(670)-R_{\mathrm{rs}}(490)\right)^{*}(555-490) /(670-490) .
\end{aligned}
$$

Note that the first group defines the spectral slope at 490 and $555 \mathrm{~nm}$, respectively, while the second group defines the spectral curvature at $555 \mathrm{~nm}$ relative to the two neighboring wavelengths. In particular, the first curvature (i.e., relative to 443 and $670 \mathrm{~nm}$ ) is defined by $\mathrm{Hu}$ et al. [14] as the CI, which was used to estimate clear-water $\mathrm{Chl}$ through nonlinear regression. In the algorithm testing and evaluation, the kernel function of SVR was selected to be the radial basis function (RBF). There are two main reasons behind this choice. One is that the RBF kernel function required relatively fewer preassigned parameters than other kernel functions, which also performed generally well with relatively a small data set (i.e., 638 pairs of $R_{\mathrm{rs}}$ and $\mathrm{Chl}$ from the NOMAD data set). Two is that the RBF kernel function led to a better performance than those from the linear, polynomial, and sigmoid kernel functions.

Because Chl distribution in nature tends to be log normal [47] for either the NOMAD data set or satellite-derived global Chl data (see Fig. 1), it is natural to perform the model training using log-transformed $\mathrm{Chl}$ (i.e., $\mathrm{Ch}_{\log }$ ) instead of Chl. However, the analysis of the correlation between various $R_{\mathrm{rs}}$ combinations and $\mathrm{Chl}_{\text {log }}$ indicated higher correlation with
$1 / \mathrm{Ch}_{\log }$ than with $\mathrm{Ch}_{\log }$. Then, $1 / \mathrm{Ch}_{\log }$ was used as the dependent variable to train the SVR model. To avoid infinite $1 / \mathrm{Chl}_{\log }$ when $\mathrm{Chl}$ approaches $1.0 \mathrm{mg} \mathrm{m}^{-3}$, the range of the $\log$-transformed Chl was used to "normalize" $1 / \mathrm{Chl}_{\log }$ as

$$
\mathrm{Chl}_{\log }^{\prime}=1 /\left(\mathrm{Chl}_{\log }+\mathrm{Ch}_{\log , \text { max }}^{\text {Train }}-\mathrm{Chl}_{\log , \text { min }}^{\text {Train }}\right)
$$

where $\mathrm{Ch}_{\log }$ is the log-transformed $\mathrm{Chl}$, and $\mathrm{Ch}_{\log , \text { max }}^{\text {Train }}$ and $\mathrm{Chl}_{\log , \text { min }}^{\text {Train }}$ are the maximum and minimum log-transformed Chl in the training data set. In order to improve the SVR performance, Chl' $\log$ was further normalized as

$$
\mathrm{Chl}_{\log }^{\prime \prime}=\frac{\mathrm{Chl}_{\log }^{\prime}-\mu}{\sigma}
$$

where $\mu$ and $\sigma$ are the mean and standard deviation of the logtransformed Chl, respectively. In the SVR training, the data pairs of Chllog" and its corresponding spectral $R_{\mathrm{rs}}$ were used. In application of the trained SVR algorithm to satellite-derived spectral $R_{\mathrm{rs}}$, the output was Chllog", which was converted to Chl using the above equations.

The training used wavelengths of 443, 490, 555, and $670 \mathrm{~nm}$ because most ocean color sensors have these four bands. When the wavelengths of a specific sensor are slightly different from the above (e.g., MODIS band is at 547 instead of $555 \mathrm{~nm}$ ), a conversion factor, based on field measured $R_{\mathrm{rs}}$ from the NOMAD data set, is applied to satellite-retrieved $R_{\mathrm{rs}}$ to convert to one of the four wavelengths above. Such a conversion follows the same approach of [14], which is also currently used as the standard practice in the NASA software package SeaDAS (Jeremy Werdell, NASA GSFC, personal communication). Comparison between sensor-specific SVR algorithms and such a "unified" algorithm indicated that although the former led to slightly lower uncertainties (see below), the latter led to much better cross-sensor consistency, therefore was selected in this study.

To put the SVR algorithm in the context of the mainstream algorithms, two other algorithms are used here as the references. One is the traditional blue/green band ratio algorithm [31], with recent updates by O'Reilly and Werdell [12]. The algorithm estimates $\mathrm{Chl}$ from $R_{\mathrm{rs}}$ ratios between blue bands and a green band. For SeaWiFS, the algorithm takes the form of

$$
\begin{aligned}
R & =\max \left(R_{\mathrm{rs}, 443}, R_{\mathrm{rs}, 490}, R_{\mathrm{rs}, 510}\right) / R_{\mathrm{rs}, 555} \\
\chi & =\log _{10}(R) \\
y & =a_{0}+a_{1} \cdot \chi+a_{2} \cdot \chi^{2}+a_{3} \cdot \chi^{3}+a_{4} \cdot \chi^{4} \\
\mathrm{Chl} & =10^{y} .
\end{aligned}
$$

In the above equations, $a_{0}-a_{4}$ are the algorithm coefficients determined through nonlinear regression between fieldmeasured $\mathrm{Chl}$ and $R_{\mathrm{rs}}$ in the NOMAD data set. In the version 6 algorithm $(\mathrm{OC} 4 \mathrm{v} 6)$, the regression coefficients are $a_{0}-a_{4}=$ $0.3272,-2.9940,2.7218,-1.2259$, and -0.5683 , respectively. Because of a lack of the 510-nm band, MODISA uses 443, 488 , and $547 \mathrm{~nm}$ to form a similar OC3v6 algorithm with coefficients determined using the same approach. Collectively, they are called OC $x$ algorithms. 
Another algorithm is the OCI algorithm [14], which is a hybrid between the OCx algorithm and a CI algorithm. The $\mathrm{CI}$ algorithm takes the following form:

$$
\begin{aligned}
& \mathrm{CI}=R_{\mathrm{rs}, 555}-\left[R_{\mathrm{rs}, 443}+(555-443) /(670-443)\right. \\
& \times\left(R_{\mathrm{rs}, 670}-R_{\mathrm{rs}, 443)]}\right. \\
& \log _{10}(\mathrm{Chl})=a_{0}+a_{1} \times \mathrm{CI} \quad[\text { for } \mathrm{CI} \leq-0.0005] \text {. }
\end{aligned}
$$

In the above equation, $a_{0}$ and $a_{1}$ are the algorithm coefficients determined through nonlinear regression between fieldmeasured $\mathrm{Chl}$ and $R_{\mathrm{rs}}$ in the NOMAD data set. In [14], they were determined to be $a_{0}=-0.4909$ and $a_{1}=$ 191.6590. The CI algorithm is only applicable for clear waters $\left(\mathrm{Chl}<0.25 \mathrm{mg} \mathrm{m}^{-3}\right)$. The $\mathrm{OC} x$ algorithm is used for more productive waters $\left(\mathrm{Chl}>0.4 \mathrm{mg} \mathrm{m}^{-3}\right.$ ) when applied to satellite data processing. For intermediate $\mathrm{Chl}$ (between 0.25 and 0.4 ), a weighted average is used. Collectively, the algorithm is termed as OCI.

\section{Algorithm Evaluation: SeaBASS and Satellite Data}

All algorithms were evaluated using the same data sets, from both in situ and satellite measurements. As in previous works [13], [14], the field-collected Chl data available from the NASA SeaBASS ([48], Table I) were used to evaluate the satellite-derived Chl, where the latter was obtained after applying the Chl algorithms to the satellite-derived $R_{\mathrm{rs}}(\lambda)$. The flowchart in Fig. 2 shows how SeaDASS data are used to evaluate the algorithm performance after application to satellite data.

Following the community standard, the following NASA recommended criteria, were used to find the satellite-in situ matching pairs: sensor zenith angle $<56^{\circ}$; solar zenith angle $<70^{\circ}$; bathymetry $>30 \mathrm{~m} ;<3$-h time difference between in situ and satellite measurements; median value of coefficients of variation $(\mathrm{CV}$, calculated as standard deviation divided by mean) of several products ( $R_{\mathrm{rs}}$ of $412-555 \mathrm{~nm}$, aerosol optical thickness at $865 \mathrm{~nm})<15 \%$ for the $5 \times 5$-pixel window centered at the in situ station; difference between simulated and measured surface irradiance $<100 \%$; and $>50 \%$ pixels in the $5 \times 5$ box must be valid (i.e., not associated with any of the standard quality-control flags such as stray light, high glint, and so on) [49]. A total of 1145 matching pairs were obtained for SeaWiFS between 1998 and 2010, and 331 matching pairs were obtained for MODIS Aqua between 2002 and 2010, respectively. These are basically the same data sets as used in [13] and [14].

From the matching pairs, several statistical measures were used to gauge the similarity (or difference) between the satellite $\left(y_{i}^{\prime}\right)$ and in situ $\left(y_{i}\right)$ Chl data, among which are

Median absolute difference (MRD)

$$
\begin{aligned}
& =10^{\left(\frac{1}{n} \sum_{i=1}^{n}\left|\log y_{i}^{\prime}-\log y_{i}\right|\right)} \\
\text { Bias } & =10^{\left(\frac{1}{n} \sum_{i=1}^{n}\left(\log y_{i}^{\prime}-\log y_{i}\right)\right)}
\end{aligned}
$$

Mean relative difference (MRD)

$$
=\frac{1}{n} \sum_{i=1}^{n}\left|\frac{y_{i}^{\prime}-y_{i}}{y_{i}}\right|
$$

Root-mean-square difference (RMSD)

$$
=\sqrt{\frac{1}{n} \sum_{i=1}^{n}\left(\frac{y_{i}^{\prime}-y_{i}}{y_{i}}\right)^{2}}
$$

Unbiased MRD (UMRD)

$$
=\frac{1}{n} \sum_{i=1}^{n}\left|\frac{2\left(y_{i}^{\prime}-y_{i}\right)}{y_{i}^{\prime}+y_{i}}\right|
$$

Unbiased RMSD (URMSD)

$$
\begin{aligned}
& =\sqrt{\frac{1}{n} \sum_{i=1}^{n}\left(\frac{2\left(y_{i}^{\prime}-y_{i}\right)}{y_{i}^{\prime}+y_{i}}\right)^{2}} \\
\text { Mean ratio } & =\frac{1}{n} \sum_{i=1}^{n} \frac{y_{i}^{\prime}}{y_{i}} \\
\text { Median ratio } & =\text { median }\left(\frac{y_{i}^{\prime}}{y_{i}}\right) .
\end{aligned}
$$

In the current literature, various forms of the above statistical measures have been used to gauge algorithm performance. The use of all these forms is to put our results in the context of the published works. Also note that we use the term "difference" (D) instead of "error" (E) in these statistical measures because in situ data also contain some degrees of uncertainties. The use of the "unbiased" terms is to account for the fact that even though in situ measurements are usually considered as the "truth," these measurements in reality may also contain large uncertainties. When the in situ $\mathrm{Chl}$ are very small and are biased low, the use of them in the denominator may yield unrealistic large error terms. Therefore, instead of having the in situ data in the denominator, the satellite data are also used in the denominator in the "unbiased" measures above. For the same reason, the statistical measures are termed as "differences" rather than "errors."

In addition to algorithm evaluations using satellite-in situ matching pairs, the algorithms were also evaluated in their ability to yield consistent data products from two different sensors (e.g., SeaWiFS versus MODISA and MODISA versus VIIRS), and in their tolerance to noise. In the cross-sensor consistency evaluation, global daily $R_{\mathrm{rs}}$ data at $9-\mathrm{km}$ resolution from the three sensors for selected months were obtained from the NASA GSFC (https://oceancolor.gsfc.nas.agov, data accessed in June 2018). The SVR algorithm was applied to the global daily $R_{\mathrm{rs}}$ data from each of the three sensors to estimate global daily Chl distributions, and compare with the global Chl data derived from the OCI and OCx algorithms. The global daily $\mathrm{Chl}$ distributions from the three algorithms (SVR, OCI, and OCx) and three sensors were then used to estimate monthly $\mathrm{Chl}$ distributions. In the noise tolerance evaluation, daily snapshot data of selected data granules over ocean gyres were obtained, where Chl distributions were derived in a similar fashion as above. Then, the snapshot Chl images were first inspected visually, and then analyzed for image noise following the approach of [14]. The assumption behind the noise evaluation is simple: in an ocean gyre away from major nutrient sources, Chl should be stable in both space and time (i.e., minimal pixel-to-pixel variations and day-to-day variations). Then, the standard deviation of 
TABLE II

Evaluation of SeaWifS-Derived Chl Using SeaBASS In Situ Chl and Three Algorithms: OC4, SVR (This Study), and OCI. Note That OCI SWITCHES to CI FOR CHL $<0.25 \mathrm{mg} \mathrm{m}^{-3}$. GRAPHICAL Form Is PRESENTED IN FIGS. 3 AND 4

\begin{tabular}{|c|c|c|c|c|c|c|c|c|c|}
\hline & \multirow[b]{2}{*}{ SVR } & \multirow[b]{2}{*}{ OC4 } & \multirow[b]{2}{*}{ OCI } & \multicolumn{3}{|c|}{ in-situ $\mathrm{Chl}<1 \mathrm{mg} / \mathrm{m}^{3}$} & \multicolumn{3}{|c|}{ in-situ $\mathrm{Chl}<0.25 \mathrm{mg} / \mathrm{m}^{3}$} \\
\hline & & & & SVR & $\mathrm{OC4}$ & $\mathrm{OCI}$ & SVR & $\mathrm{OC} 4$ & OCI \\
\hline MAD & 1.57 & 1.59 & 1.59 & 1.51 & 1.54 & 1.54 & 1.53 & 1.55 & 1.46 \\
\hline Bias & 0.95 & 0.97 & 0.96 & 1.15 & 1.15 & 1.13 & 1.24 & 1.29 & 1.24 \\
\hline MRD & $51.9 \%$ & $56.8 \%$ & $56.2 \%$ & $59.2 \%$ & $66.2 \%$ & $65.2 \%$ & $75.2 \%$ & $87.4 \%$ & $53.1 \%$ \\
\hline RMSD & $173.7 \%$ & $261.3 \%$ & $260.7 \%$ & $211.8 \%$ & $321.0 \%$ & $320.3 \%$ & $299.7 \%$ & $459.2 \%$ & $90.7 \%$ \\
\hline UMRD & $42.1 \%$ & $42.6 \%$ & $42.9 \%$ & $39.2 \%$ & $40.5 \%$ & $40.8 \%$ & $39.5 \%$ & $40.5 \%$ & $36.3 \%$ \\
\hline URMSD & $54.2 \%$ & $55.2 \%$ & $55.3 \%$ & $50.0 \%$ & $51.8 \%$ & $51.8 \%$ & $52.0 \%$ & $53.3 \%$ & $46.6 \%$ \\
\hline Mean ratio & 1.17 & 1.24 & 1.22 & 1.38 & 1.45 & 1.43 & 1.58 & 1.72 & 1.39 \\
\hline Median ratio & 0.96 & 1.00 & 1.00 & 1.14 & 1.15 & 1.15 & 1.12 & 1.15 & 1.16 \\
\hline$R^{2}$ linear & 0.51 & 0.49 & 0.49 & 0.48 & 0.34 & 0.34 & 0.05 & 0.02 & 0.32 \\
\hline$R^{2} \log$ & 0.79 & 0.78 & 0.78 & 0.70 & 0.67 & 0.67 & 0.36 & 0.34 & 0.40 \\
\hline$N$ & 1145 & 1145 & 1145 & 748 & 748 & 748 & 357 & 357 & 357 \\
\hline
\end{tabular}
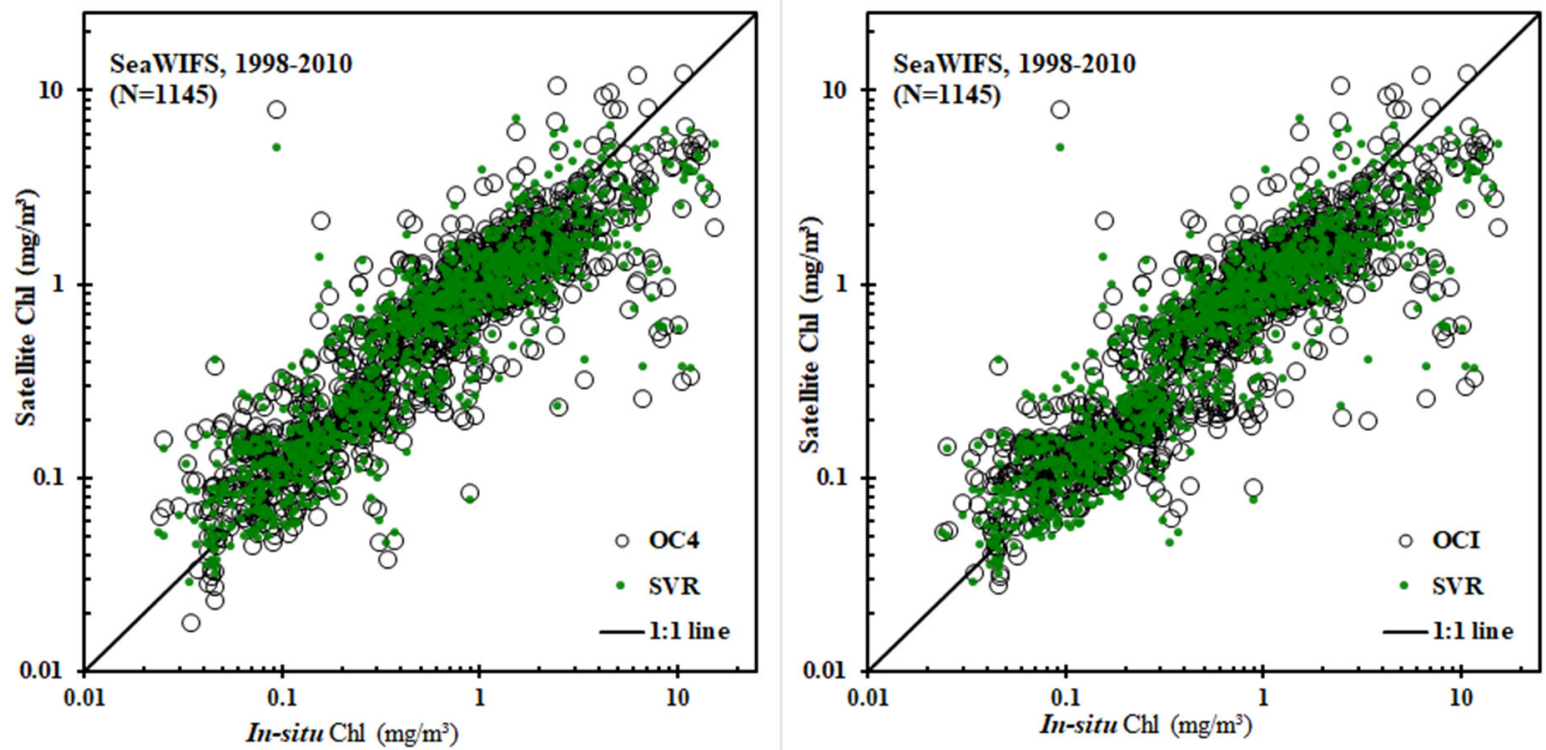

Fig. 3. Evaluation of SeaWiFS-derived Chl using SeaBASS in situ Chl and three algorithms: OC4, SVR (this study), and OCI. (a) Visual comparison between OC4 and SVR. (b) Visual comparison between OCI and SVR. Algorithm performance statistics are listed in Table II.

a $3 \times 3$ pixel window is regarded as the noise, whose magnitude is referenced against the mean value of the $3 \times 3$ pixel window. This calculation was repeated for each $3 \times 3$ pixel window in the individual images, with results partitioned according to the mean Chl values of the $3 \times 3$ pixel windows.

\section{RESUlts}

\section{A. Algorithm Performance Evaluation With Field Data}

1) SeaWiFS: Table II shows the statistical measures of the SVR algorithm when applied to SeaWiFS $R_{\mathrm{rs}}$ data, when the concurrent and colocated field-measured Chl were used as the reference for the evaluation (see Section II-C). The graphical forms of the evaluation are presented in Fig. 3 for the entire data set and Fig. 4 for the major oceans. In Table II, the statistical measures are listed separately for the 1) entire data set; 2) data with $\mathrm{Chl}<1 \mathrm{mg} \mathrm{m}^{-3}$; and 3) data with $\mathrm{Chl}<0.25 \mathrm{mg} \mathrm{m}^{-3}$. For comparison, the performance of the
OCx and OCI algorithms is also presented in Table II and Figs. 3 and 4.

From Table II, when all data are used in the evaluation, the SVR algorithm shows slightly better performance than OCx and OCI, as indicated by all but the "median ratio" statistical measures. When the data are restricted to Chl $<1 \mathrm{mg} \mathrm{m}^{-3}$, the improvement of SVR over OCx and OCI appears to increase, but the increase is small. When the data are restricted to $\mathrm{Chl}<0.25 \mathrm{mg} \mathrm{m}^{-3}$ (for this range, the OCI algorithm switches to the CI algorithm), SVR performance is still better than OCx, but worse than OCI (except for the median ratio values).

The algorithm differences can also be examined graphically in Fig. 3(a) for SVR versus OCx and in Fig. 3(b) for SVR versus OCI. In Fig. 3(a), SVR resulted in a narrower data spread around the 1:1 line when compared with $\mathrm{OC} x$, especially for those extreme outliers. However, for $\mathrm{Chl}>2 \mathrm{mg} \mathrm{m}^{-3}$, SVR Chl is biased low and the bias appears to be more 

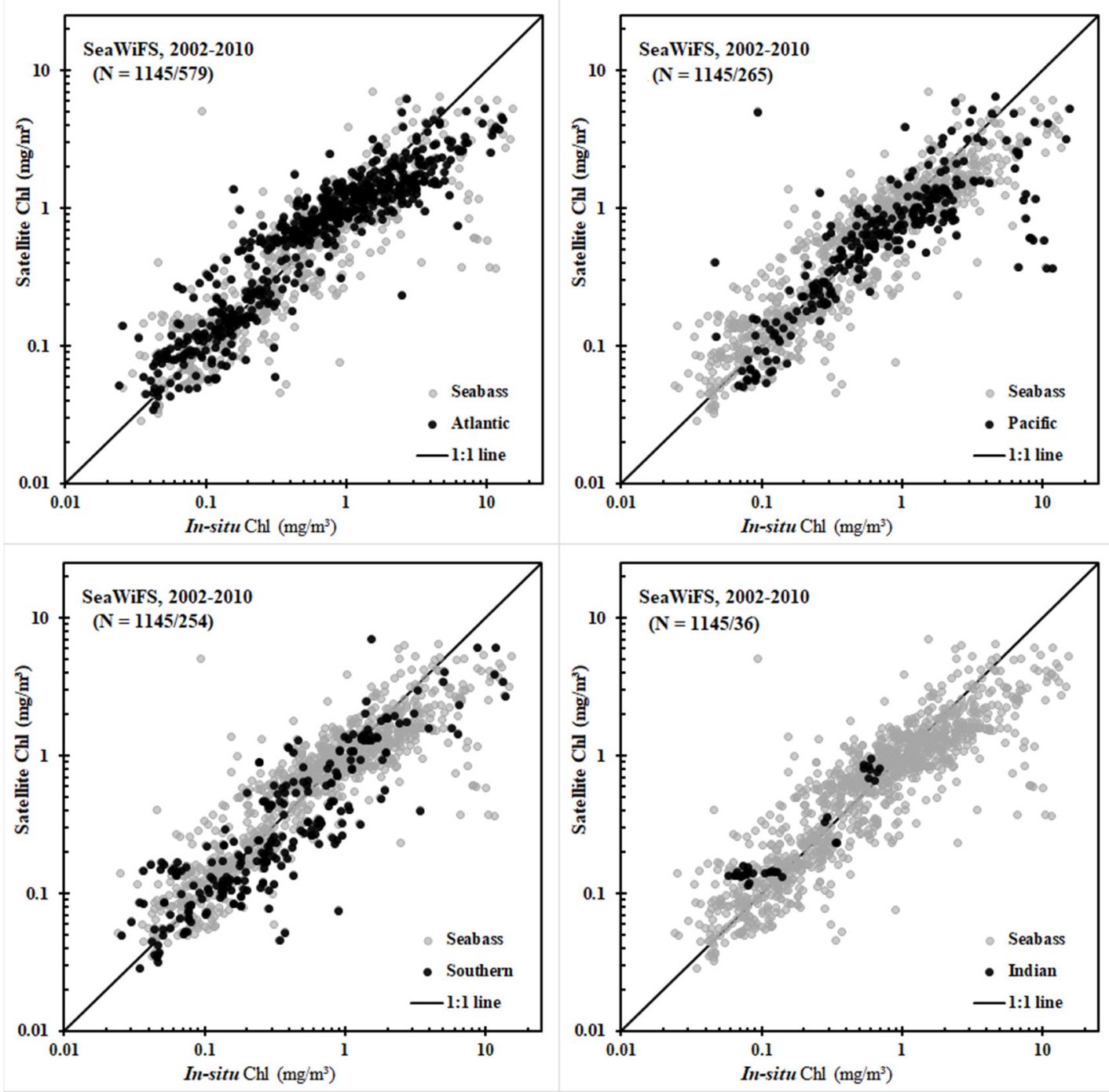

Fig. 4. Same as Fig. 3, but only SeaWiFS SVR Chl is compared with SeaDAS in situ Chl here, with data partitioned to the Atlantic Ocean, Pacific Ocean, Southern Ocean, and Indian Ocean, respectively.

severe than OCx. In Fig. 3(b), the data spread in SVR Chl is lower than in OCI for $\mathrm{Chl}>1 \mathrm{mg} \mathrm{m}^{-3}$ but the difference for $\mathrm{Chl}<0.25 \mathrm{mg} \mathrm{m}^{-3}$ is not clear. The visual inspection results are consistent with those listed in Table II.

Similar to other empirical algorithms, the performance of the SVR algorithm may be different across major ocean basins (see Fig. 4). This effect has been demonstrated for the OCx algorithm in [17] and for the OCI algorithm in [50], as a result of different proportions of CDOM and detrital particles relative to phytoplankton pigment absorption in different oceans. For extremely clear waters $\left(<0.1 \mathrm{mg} \mathrm{m}^{-3}\right)$ in the Pacific, the SVR Chl may be biased low [see Fig. 4(b)], but for most waters in the Indian Ocean, the SVR Chl may be biased high [see Fig. 4(d)]. However, the number of matching pairs under these circumstances is too low to make a solid conclusion, suggesting the necessity of collecting more field data in these regions.

2) MODISA: The same observations from SeaWiFS can be extended to MODISA for the three algorithms. From all statistical measures, Table III shows that the
SVR algorithm performs better than OCx and OCI for either all data or data restricted to $\mathrm{Chl}<1 \mathrm{mg} \mathrm{m}^{-3}$. For data with Chl $<0.25 \mathrm{mg} \mathrm{m}^{-3}$, SVR performance is still better than OC $x$, but becomes worse than OCI.

The graphical form of these algorithm comparisons in Fig. 5 reveals the performance difference visually. For most data range, SVR resulted in a tighter relationship than $\mathrm{OC} x$ and OCI between MODISA Chl and in situ Chl. Only when Chl is $<0.25 \mathrm{~m}^{-3}$ does SVR appear to be slightly worse than OCI. Similar to the SeaWiFS evaluation results, the MODISA results suggest that when Chl is $>2 \mathrm{mg} \mathrm{m}^{-3}$, SVR Chl appears to be biased low.

When partitioned to different major ocean basins, the SVR shows similar performance for MODISA (see Fig. 6) as for SeaWiFS (see Fig. 4). For extremely clear waters $\left(<0.1 \mathrm{mg} \mathrm{m}^{-3}\right)$ in the Pacific the SVR Chl appears to be biased low [see Fig. 6(b)], but for the Indian Ocean the SVR Chl appears to be biased high [see Fig. 6(d)]. However, there are only four matching pairs for the former and two matching pairs for the latter, making these observations statistically 
TABLE III

Evaluation of MOdis A-Derived Chl Using SeabASS In Situ Chl and Three Algorithms: OC4, SVR (This STUdy), and OCI. Note That OCI SWITCHES to CI FOR CHL $<0.25 \mathrm{mg} \mathrm{m}^{-3}$. GraphiCAL Form Is PRESENTED IN Figs. 5 AND 6

\begin{tabular}{|c|c|c|c|c|c|c|c|c|c|}
\hline & \multirow[b]{2}{*}{ SVR } & \multirow[b]{2}{*}{$\mathrm{OC} 3$} & \multirow[b]{2}{*}{$\mathrm{OCI}$} & \multicolumn{3}{|c|}{ in-situ $\mathrm{Chl}<1 \mathrm{mg} / \mathrm{m}^{3}$} & \multicolumn{3}{|c|}{ in-situ $\mathrm{Chl}<0.25 \mathrm{mg} / \mathrm{m}^{3}$} \\
\hline & & & & SVR & $\mathrm{OC} 3$ & $\mathrm{OCI}$ & SVR & $\mathrm{OC} 3$ & $\mathrm{OCI}$ \\
\hline MAD & 1.52 & 1.62 & 1.62 & 1.43 & 1.61 & 1.62 & 1.35 & 1.41 & 1.32 \\
\hline Bias & 0.98 & 1.16 & 1.18 & 1.23 & 1.35 & 1.38 & 1.19 & 1.21 & 1.19 \\
\hline MRD & $43.4 \%$ & $67.3 \%$ & $68.8 \%$ & $46.8 \%$ & $77.9 \%$ & $80.2 \%$ & $40.5 \%$ & $47.0 \%$ & $34.6 \%$ \\
\hline RMSD & $63.5 \%$ & $159.1 \%$ & $161.3 \%$ & $71.5 \%$ & $188.6 \%$ & $191.5 \%$ & $68.5 \%$ & $81.2 \%$ & $50.9 \%$ \\
\hline UMRD & $39.6 \%$ & $44.6 \%$ & $44.7 \%$ & $34.4 \%$ & $44.7 \%$ & $44.8 \%$ & $29.1 \%$ & $32.9 \%$ & $27.0 \%$ \\
\hline URMSD & $51.7 \%$ & $57.1 \%$ & $57.4 \%$ & $44.0 \%$ & $56.2 \%$ & $56.5 \%$ & $39.5 \%$ & $44.3 \%$ & $35.0 \%$ \\
\hline Mean ratio & 1.14 & 1.44 & 1.46 & 1.35 & 1.64 & 1.67 & 1.30 & 1.35 & 1.26 \\
\hline Median ratio & 1.04 & 1.18 & 1.18 & 1.20 & 1.32 & 1.33 & 1.11 & 1.14 & 1.10 \\
\hline$R^{2}$ linear & 0.40 & 0.37 & 0.37 & 0.57 & 0.13 & 0.13 & 0.52 & 0.42 & 0.63 \\
\hline$R^{2} \log$ & 0.78 & 0.75 & 0.75 & 0.75 & 0.74 & 0.74 & 0.71 & 0.65 & 0.71 \\
\hline$N$ & 331 & 331 & 331 & 212 & 212 & 221 & 63 & 63 & 63 \\
\hline
\end{tabular}
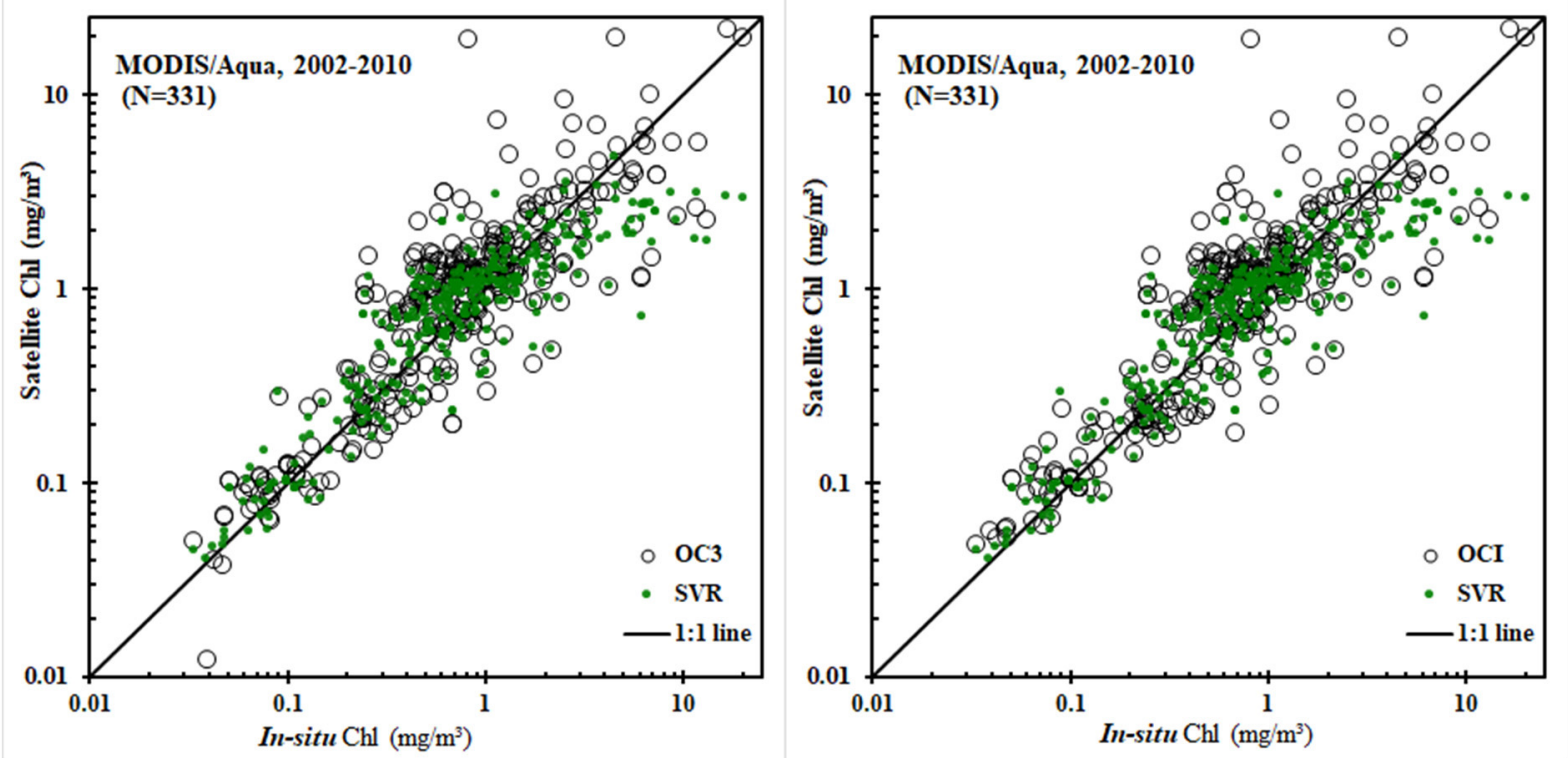

Fig. 5. Evaluation of MODISA-derived Chl using SeaBASS in situ Chl and three algorithms: OC3, SVR (this study), and OCI. (a) Visual comparison between OC3 and SVR. (b) Visual comparison between OCI and SVR. Algorithm performance statistics are listed in Table III.

meaningless. Therefore, to make a solid conclusion, more field data are required for these regions.

Overall, the algorithm evaluations of both SeaWiFS and MODISA data yielded consistent results. These results suggest that for most waters $\left(<1-2 \mathrm{mg} \mathrm{m}^{-3}\right)$ SVR may yield slightly more accurate Chl retrievals than both OC $x$ and OCI, but for clear waters $\left(<0.25 \mathrm{mg} \mathrm{m}^{-3}\right)$ SVR may yield slightly worse retrievals than OCI.

\section{B. Algorithm Performance Evaluation Without Field Data}

1) Individual Sensors: Regardless of how much field data is available, they may never be enough to evaluate satellite data as a whole. This is because the global oceans are not sampled proportionally in either time or space, and each point in the field-based evaluation may carry a different weight when ocean waters corresponding to the point are considered in global validations. Such a mismatch between field data distributions and satellite data distributions is clearly shown in Fig. 1. Consequently, a perfect match between field and satellite data (i.e., no bias, mean ratio $=1.0$, very low RMSD values) may actually lead to much higher uncertainties when global satellite data are used for the same evaluation. Vice versa is also true-a poor performance in field-based evaluation does not necessarily lead to bad performance when global satellite data are used. Furthermore, cross-sensor consistency and image artifacts are difficult to reveal in field-based evaluations, making it necessary to evaluate algorithms using global satellite images.

Fig. 7 shows the mean SeaWiFS global Chl distributions in January and June 2010 derived from the OCx, OCI, and SVR algorithms. Their spatial patterns are very similar, with all major oceanographic features (equatorial upwelling, ocean gyres, high $\mathrm{Chl}$ in high-latitude seas, and coastal waters) revealed clearly. These results suggest that while slight differences exist in the algorithms when field data are used in the evaluations (Table II and Figs. 3-4), such differences are 

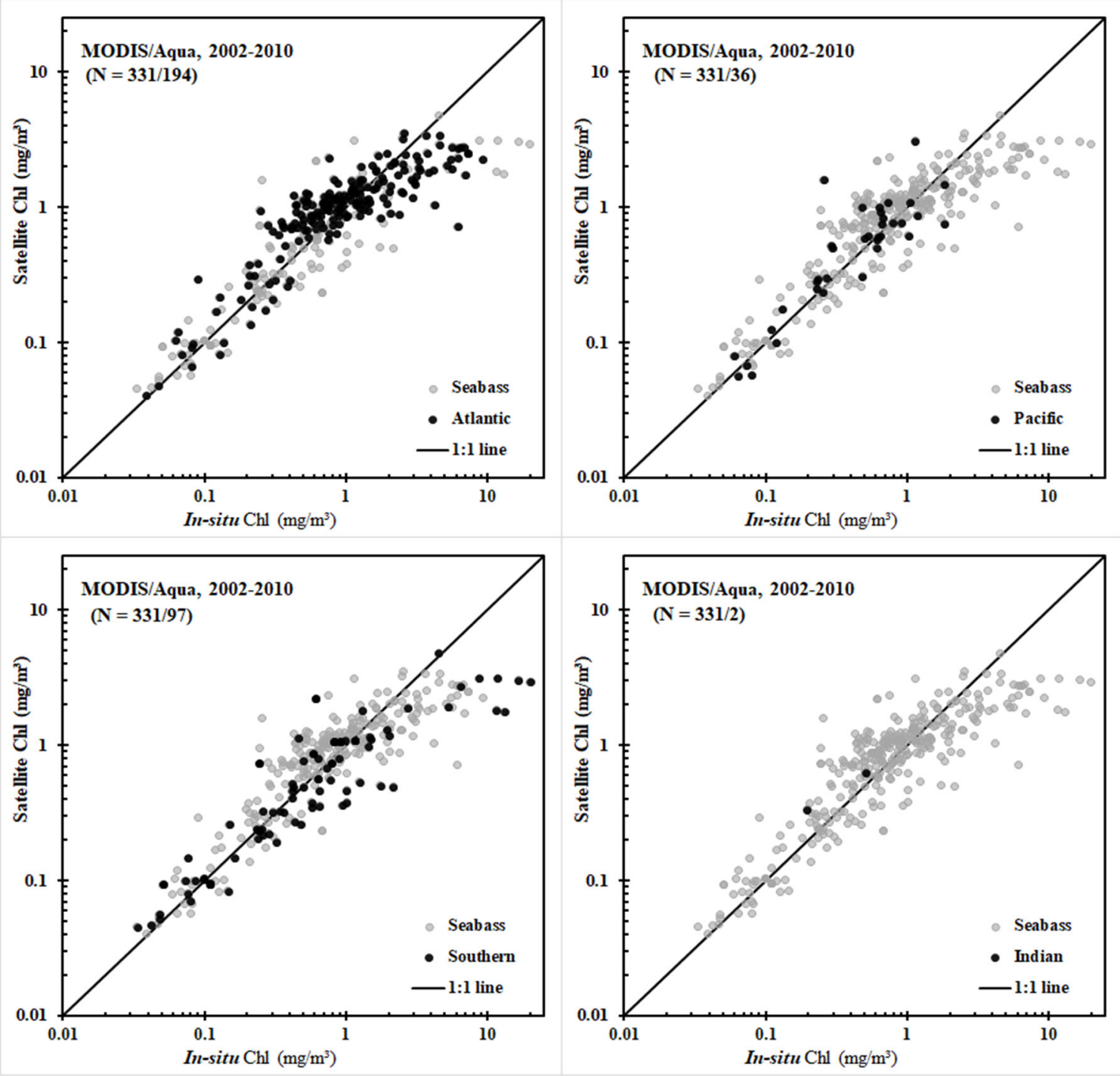

Fig. 6. Same as Fig. 5, but only MODISA SVR Chl is compared with SeaDAS in situ Chl here, with data partitioned to the Atlantic Ocean, Pacific Ocean, Southern Ocean, and Indian Ocean, respectively.

difficult to visualize when examining large-scale Chl patterns, indicating that they may perform equally well.

Global means may hide some subtle differences due to, for example, image noise or small artifacts that can only be revealed in snapshot daily images. Fig. 8 shows an example of such cases, where image noise and other artifacts are clearly visible in the OCx $\mathrm{Chl}$ image, but not as apparent in the OCI or SVR Chl image. Although the ability of SVR in revealing the ocean eddy features and other small patterns is not as good as the OCI, its improvement over OCx is significant. Such a tolerance to noise has significant impact on not only image quality, but also on data product consistency across different sensors, as revealed below.

Similar to the SeaWiFS observations, MODISA global monthly mean $\mathrm{Chl}$ data products show similar distributions from the three algorithms (see Fig. 9). All major features, including equatorial upwelling, ocean gyres, and high-latitude productive waters, are revealed clearly in all three products for both winter (January 2010) and summer (June 2010).
When evaluated using daily snapshot images, both OCI and SVR show significant noise reduction over the OCx algorithm, especially near clouds and sun glint (see Fig. 10).

The noise reduction from the SVR algorithm is quantified from SeaWiFS and MODISA measurements over ocean gyres, in reference against the $\mathrm{OC} x$ algorithm and $\mathrm{OCI}$ algorithm (see Fig. 11). For simplicity, the errors are termed as "pixelization" errors or speckling noises. Fig. 11(a) shows that for SeaWiFS measurements, pixelization errors for $\mathrm{Chl}<0.1 \mathrm{mg} \mathrm{m}^{-3}$ are $>10 \%$ from the OC $x$ algorithm, which also increase sharply with decreasing Chl. In contrast, both SVR and OCI show much reduced pixelization errors, usually $<5 \%$. Furthermore, both algorithms show relatively stable errors independent of $\mathrm{Chl}$ values. For $\mathrm{Chl}>0.2 \mathrm{mg} \mathrm{m}^{-3}$, all these algorithms approach $7 \%$ pixelization errors. Because $\sim 38 \%$ of the global oceans have Chl $<0.1 \mathrm{mg} \mathrm{m}^{-3}$ according to SeaWiFS statistics, the reduction in pixelization error appears to be significant. Similar observations are obtained from MODISA images [see Fig. 11(b)]. Although pixelization errors from the 


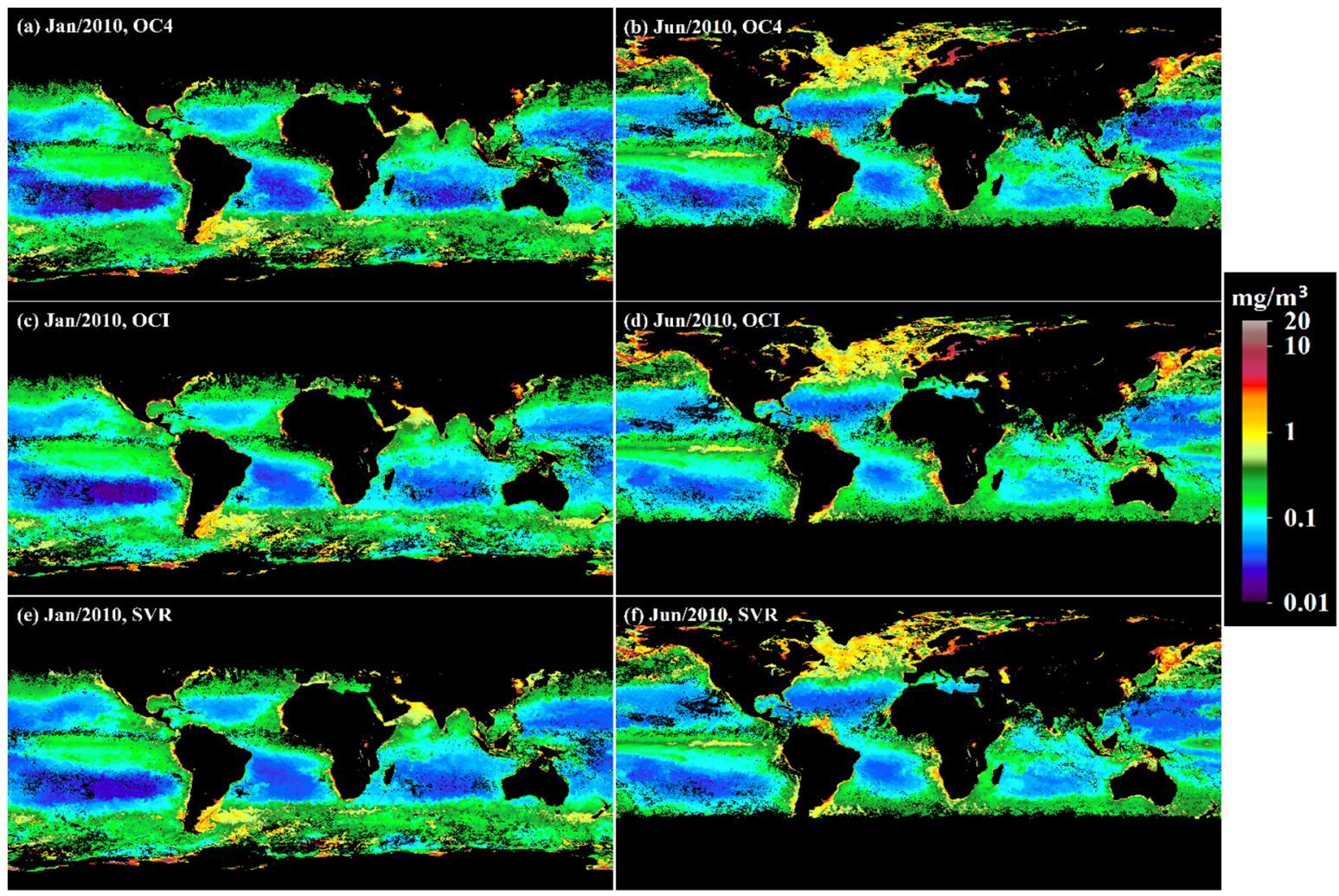

Fig. 7. SeaWiFS global Chl distributions in (a), (c), and (e) January 2010 and (b), (d), and (f) June 2010 derived from three algorithms: (a) and (b) OC4, (c) and (d) OCI, and (e) and (f) SVR.

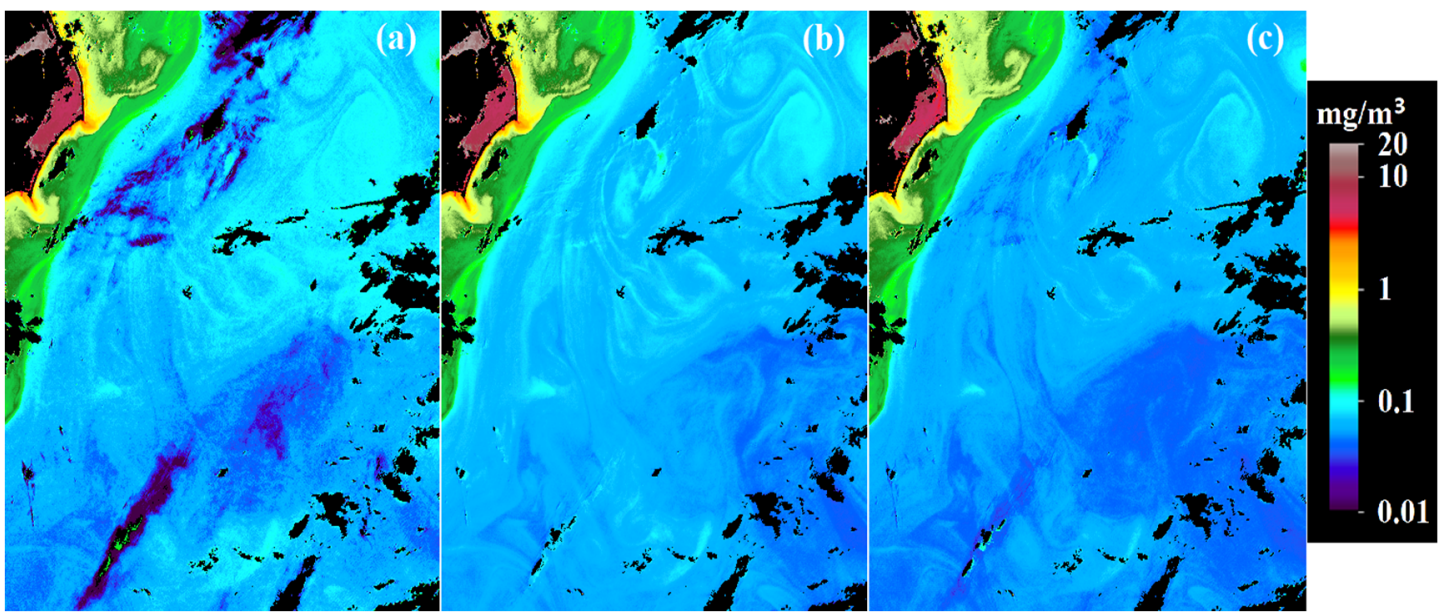

Fig. 8. Comparison between SeaWiFS Level-2 Chl distribution off the U.S. east coast on June 1, 2004, derived from three algorithms: (a) OC4, (b) OCI, and (c) SVR. The images cover a region of $28.5^{\circ}-36.5^{\circ} \mathrm{N}$ and $76.5^{\circ}-70.5^{\circ} \mathrm{W}$, the same region used in [14] when the OCI algorithm was proposed. The Level-2 quality control flags were turned off to show the eddy features.

MODISA data are much reduced from SeaWiFS data in all three algorithms due to significantly improved signal-to-noise ratios of the MODISA sensor over SeaWiFS [51], the trend among the three algorithms is the same: for $\mathrm{Chl}<0.1 \mathrm{mg} \mathrm{m}^{-3}$, $\mathrm{OC} x$ algorithm leads to much higher pixelization errors than the OCI and SVR algorithms, while all three algorithms approach the same value of $4 \%$ for $\mathrm{Chl}>0.2 \mathrm{mg} \mathrm{m}^{-3}$.

2) Cross-Sensor Consistency: The SVR algorithm tolerance to noise is also revealed from simulations, where different levels of noise $(0 \%, 5 \%, 10 \%$, and $15 \%)$ were added to the input $R_{\mathrm{rs}}$. Results in Supplementary Table S3 indicate that the algorithm performance is similar at different noise levels, suggesting the tolerance of the SVR algorithm to input $R_{\mathrm{rs}}$ noise.

For long-term studies of ocean changes in response to climate variability or human activities, cross-sensor consistency is perhaps more important than data product accuracy, as most sensors are designed to have a five-year mission life, and multidecadal data from multiple sensors are therefore required to observe long-term changes. Indeed, one of the 

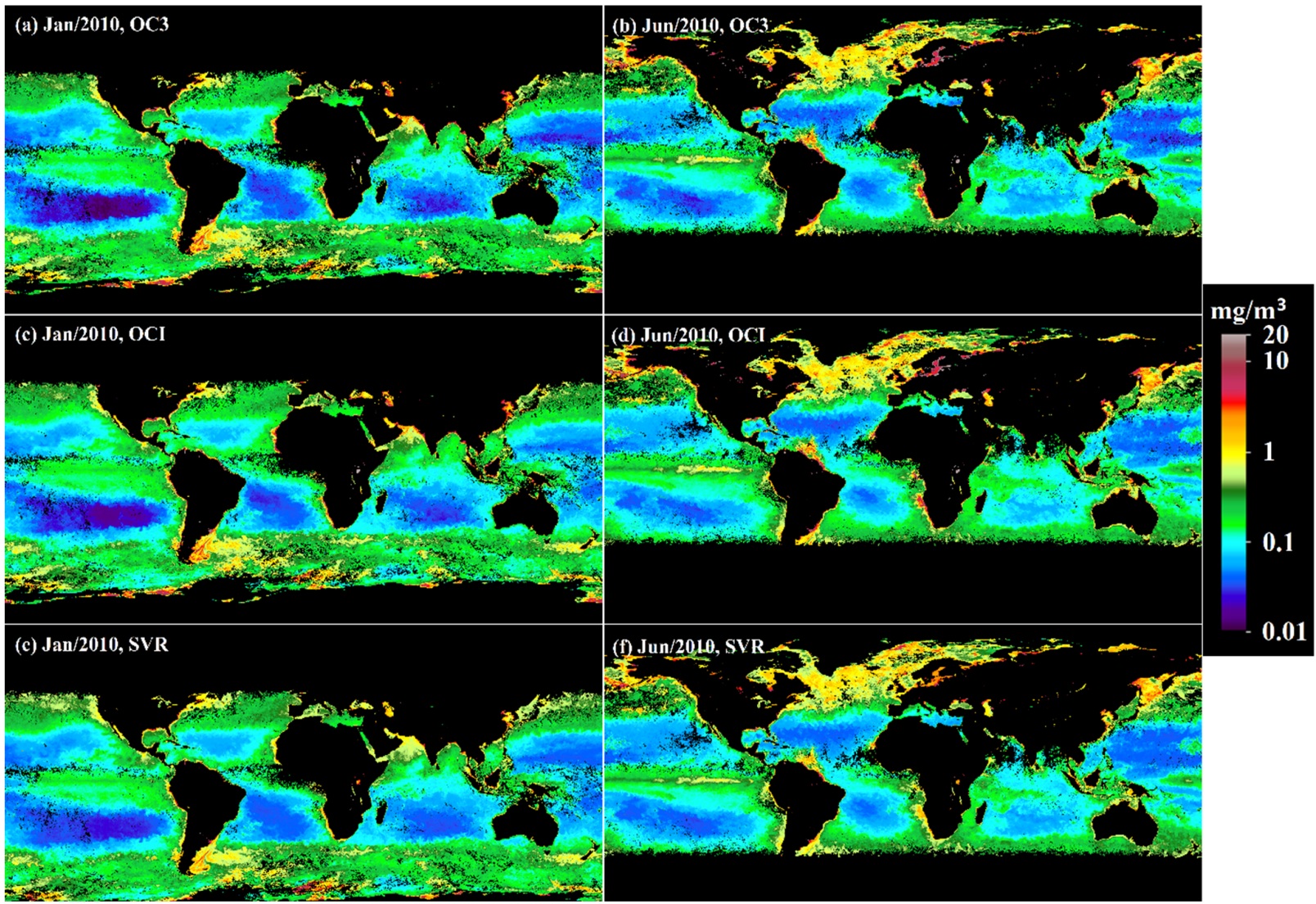

Fig. 9. MODISA global Chl distributions in (a), (c), and (e) January 2010 and (b), (d), and (f) June 2010 derived from three algorithms: (a) and (b) OC3, (c) and (d) OCI, and (e) and (f) SVR.
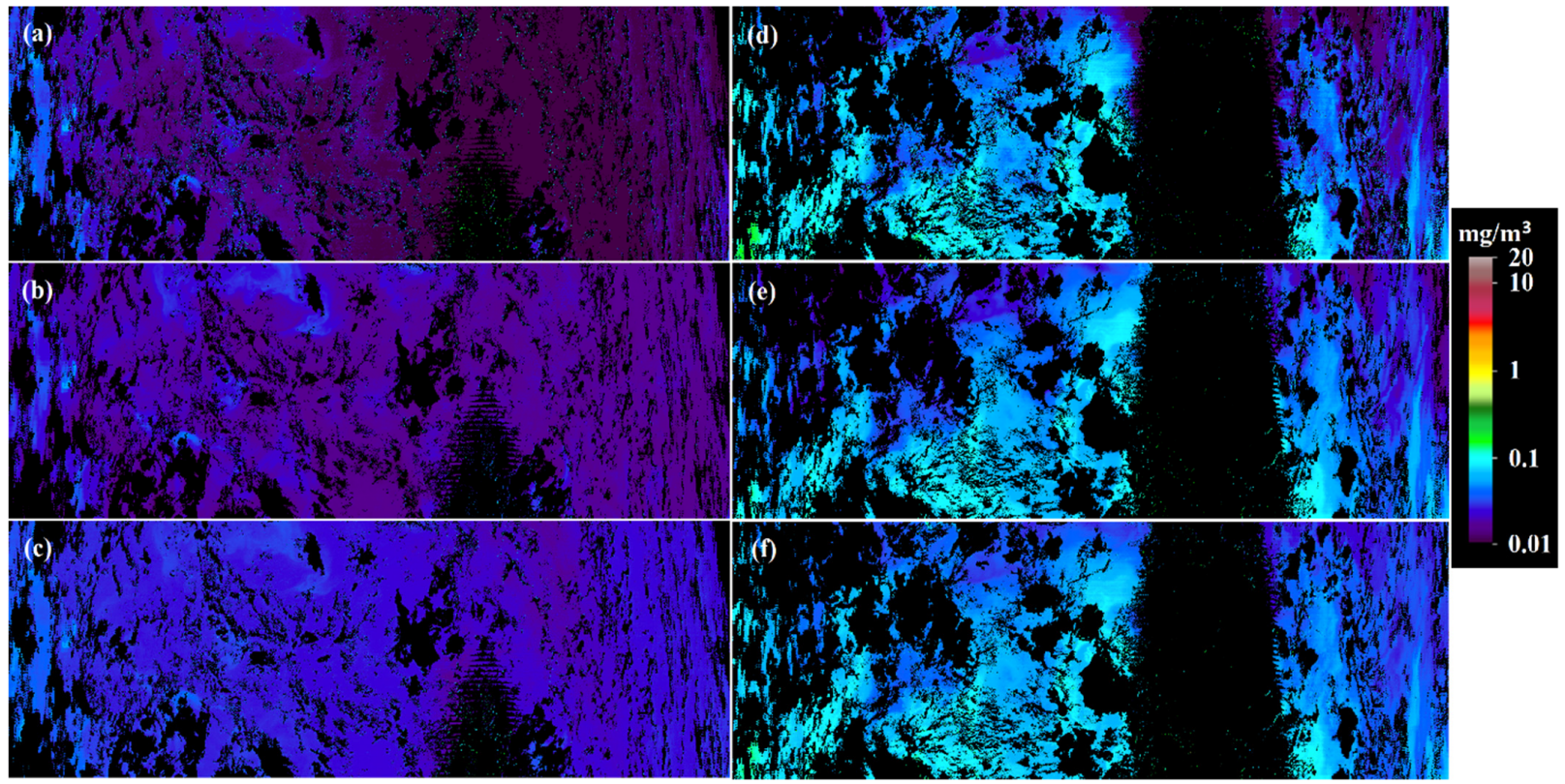

Fig. 10. Comparison between MODISA Level-2 Chl distribution in the South Pacific gyre (approximately $2200 \times 440 \mathrm{~km}$ centered at $25.2^{\circ} \mathrm{S}, 110.8^{\circ} \mathrm{W}$ ) on (a)-(c) March 4, 2003, and (d)-(f) July 27, 2003, derived from three algorithms: (a) and (d) OC3, (b) and (e) OCI, and (c) and (f) SVR. The Level-2 quality control flags were turned off to show color features and noise.

significant advantages of the OCI algorithm over the $\mathrm{OC} x$ algorithm is its ability to bring multiple sensors much closer for low-Chl waters [13], [14]. Figs. 12 and 13 show that the SVR algorithm has similar advantage to assure cross-sensor consistency.
In Fig. 12, global distributions of Chl ratios between SeaWiFS and MODISA are illustrated, where $\mathrm{Chl}$ was derived from both OCI and SVR algorithms (for brevity, results from the OCx algorithms are not shown here as they show worse cross-sensor consistency, see [14]). For each algorithm, 

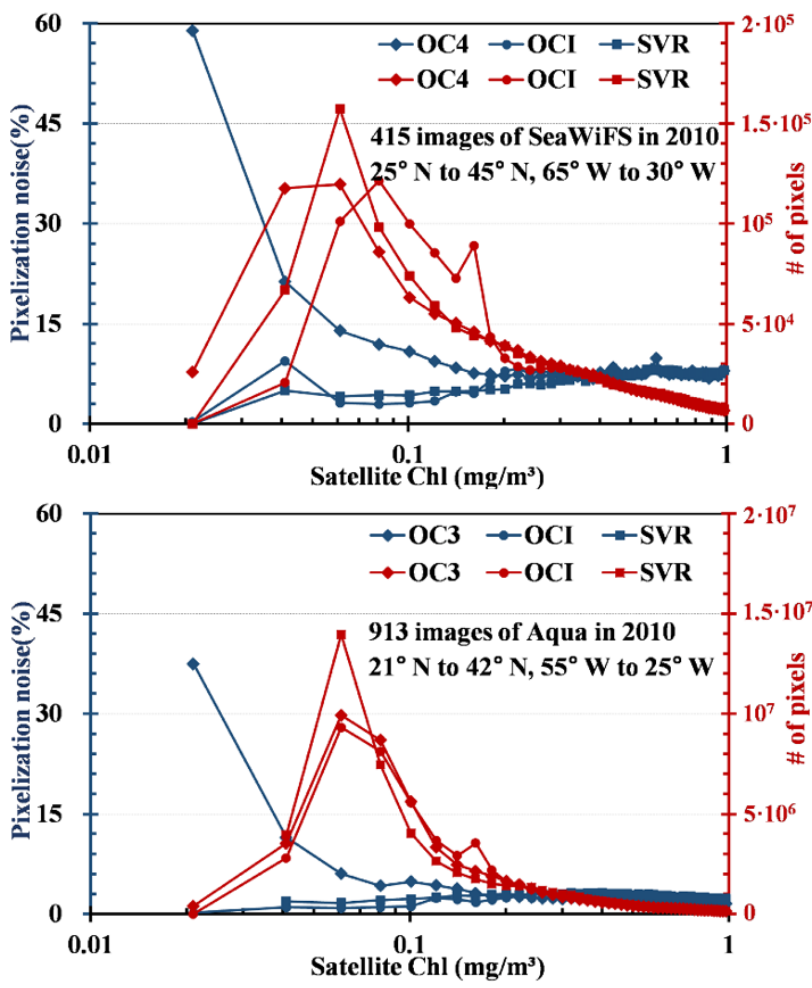

Fig. 11. Pixelization noise, estimated as the average ratio between the rms Chl and mean $\mathrm{Chl}$ of $3 \times 3$ pixels for each Chl range from multiple (a) SeaWiFS images and (b) MODISA images. The total number of pixels for each $\mathrm{Chl}$ range is also plotted (red colored, right $y$-axis). The results indicate that both OCI and SVR yielded much "cleaner" images than OC $x$ for oligotrophic oceans $\left(\mathrm{Chl}<0.1 \mathrm{mg} \mathrm{m}^{-3}\right)$.

there are differences between SeaWiFS and MODISA Chl, and these differences appear to be spatially coherent. For example, Fig. 12(a) from the OCI algorithm shows the ratios of $<1.0$ in the northern hemisphere gyre but $>1.0$ in the southern hemisphere gyre in January 2010, while Fig. 12(c) from the SVR algorithm for the same month shows the ratios of $<1.0$ in the gyres of both hemispheres. However, these differences are mostly small (within $-10 \%$ to $10 \%$, or the ratio is between 0.9 and 1.1). When viewed in data histogram statistics (Fig. 12, bottom panels), similar consistency is obtained between SeaWiFS and MODISA Chl from both OCI and SVR algorithms. However, for the same sensor, there are noticeable differences between the algorithms. For example, for January 2010, there is only one mode in the histogram $\left(\sim 0.12 \mathrm{mg} \mathrm{m}^{-3}\right)$ from the OCI algorithm, but there appear two modes $\left(\sim 0.07\right.$ and $\left.0.15 \mathrm{mg} \mathrm{m}^{-3}\right)$ from the SVR algorithm. For this analysis, it is impossible to determine which algorithm is closer to the "truth" due to lack of sufficient field data.

Similar cross-sensor consistency is obtained between VIIRS and MODISA from both OCI and SVR algorithms (see Fig. 13). From each algorithm, although there are some spatially coherent differences between the two sensors, these differences are mostly small (within $-10 \%$ to $10 \%$, or the ratio is between 0.9 and 1.1). Data statistics shown in the histograms (Fig. 13, bottom panels) also suggest cross-sensor consistency when either OCI or SVR algorithm is applied to the two sensors. Although the data statistics are pulled from a different year (2012) for VIIRS/MODISA than in Fig. 12 (2010) for SeaWiFS/MODISA, the histogram patterns for either January or June are similar in different years, indicating temporal stability of the algorithms.

\section{DISCUSSION}

\section{A. Unified Algorithm or Sensor-Specific Algorithm?}

In the past, because of the different band settings among sensors, sensor-specific algorithms have been developed to account for the differences in the number of bands, band-center wavelengths, and band passes. For example, SeaWiFS used a four-band band-ratio (OC4) algorithm but MODISA and VIIRS used a three-band band-ratio (OC3) algorithm. The most recent effort by O'Reilly and Werdell [12] further developed this concept to five-band (OC5) and six-band (OC6) band-ratio algorithms, with improved performance over the original OC4 or OC3 algorithms.

The question is why not use all six SeaWiFS bands and six MODISA bands to develop sensor-specific SVR algorithms here. After all, the sensor-unique bands (i.e., $510 \mathrm{~nm}$ on SeaWiFS and $531 \mathrm{~nm}$ on MODISA) may carry independent information from other bands, and the inclusion of the 412-nm band may account for some of the variability induced by CDOM. Indeed, our initial attempt was to use all bands from individual sensors to develop sensor-specific SVR algorithms, which did lead to slightly better performance over the sensor-independent (i.e., unified) SVR algorithm (Supplementary Tables S4 and S5 and Supplementary Figs. S1 and S2). However, two problems were encountered.

First, after the addition of the 412-nm band, although statistical measures were improved when field data were used to evaluate the algorithm performance, the algorithm generated unrealistic spatial patterns in the South Pacific and South Atlantic Gyres (Chl values are unrealistically high) when applied to SeaWiFS global data. Although the reasons are still not fully understood, we speculate that it is because most NOMAD data points are from the northern hemisphere, and lack of training data in the southern gyres may confuse the SVR algorithm when applied to these gyres because CDOM proportion in total absorption is different between the two hemispheres [50]. Second, even without the use of the 412-nm band, when the 510-nm band was used to develop a SeaWiFS-specific SVR algorithm and the 531-nm band was used to develop a MODISA-specific SVR algorithm, it is impossible to achieve similar cross-sensor consistency as shown in Fig. 12. Supplementary Fig. S3 shows the comparison between sensor-specific SVR and sensor-independent SVR for their cross-sensor consistency between SeaWiFS and MODISA. For most oceans (e.g., the Southern Ocean and Equatorial zones), the departure from 1.0 is more severe from the sensor-specific SVR, which further justifies the use of a sensor-independent (i.e., unified) SVR in this study. Similar to the SeaWiFS 510-nm and MODISA 531-nm bands, MODISA is equipped with a unique $678 \mathrm{~nm}$ to estimate solar stimulated fluorescence that is useful to assess phytoplankton physiology in open ocean waters [52] and $\mathrm{Chl}$ in optically complex coastal 

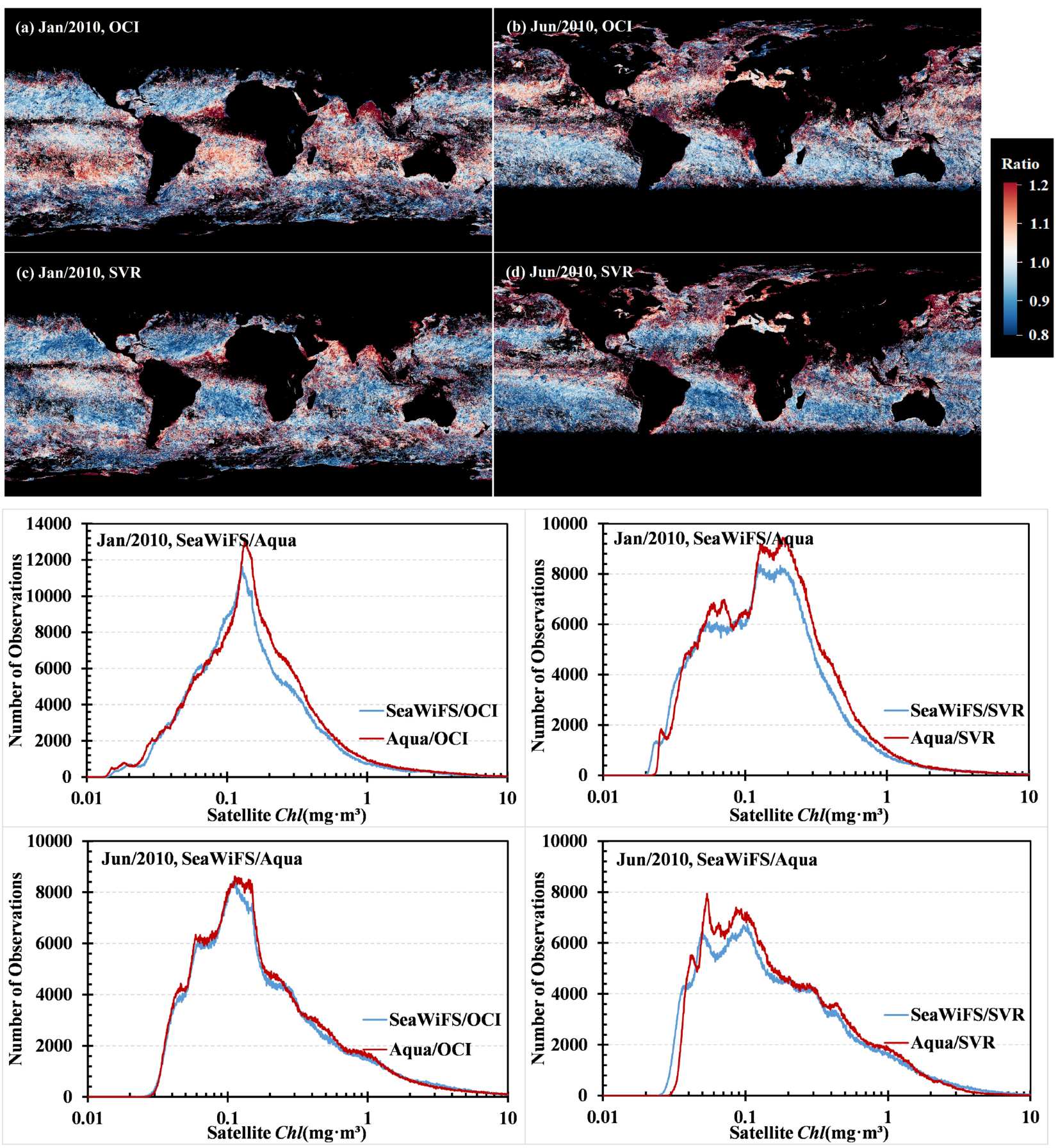

Fig. 12. Evaluation of cross-sensor consistency between SeaWiFS and MODISA using the OCI algorithm and SVR algorithm. (a) and (b) Ratio of MODISA/SeaWiFS OCI Chl for January and June 2010, respectively. (c) and (d) Ratio of MODISA/SeaWiFS SVR Chl for January and June 2010, respectively. A ratio of 1.0 indicates perfect consistency. The bottom panels show their histogram distributions. Chl data were derived from the $9-\mathrm{km}$ daily global $R_{\mathrm{rs}}$ data using the two algorithms.

waters [53]. However, the problem with this band is that it is very easy to saturate [51, Fig. 2(b)] or get contaminated by straylight, leading to $33 \%$ reduced data as compared with $\mathrm{Chl}$ ([54, Fig. 1] $3.29 \%$ for fluorescence line height (nFLH) versus $4.91 \%$ for $\mathrm{Chl}$ ).

Therefore, with a slight tradeoff, only four common bands $(443,490,555$, and $670 \mathrm{~nm})$ were used to develop a unified, sensor-independent SVR algorithm, which shows significant advantage in cross-sensor consistency when compared with a sensor-specific approach. In the unified approach, the slight differences in band centers and band passes across different sensors are taken care of by converting the satelliteretrieved $R_{\mathrm{rs}}$ to these wavelengths, and such conversions are currently available in NASA's software package (SeaDAS) [Jeremy Werdell, NASA/Ocean Biology Processing Group (OBPG), personal communication], which are also applied to the sensor-independent OCI algorithm as the default option by NASA. 

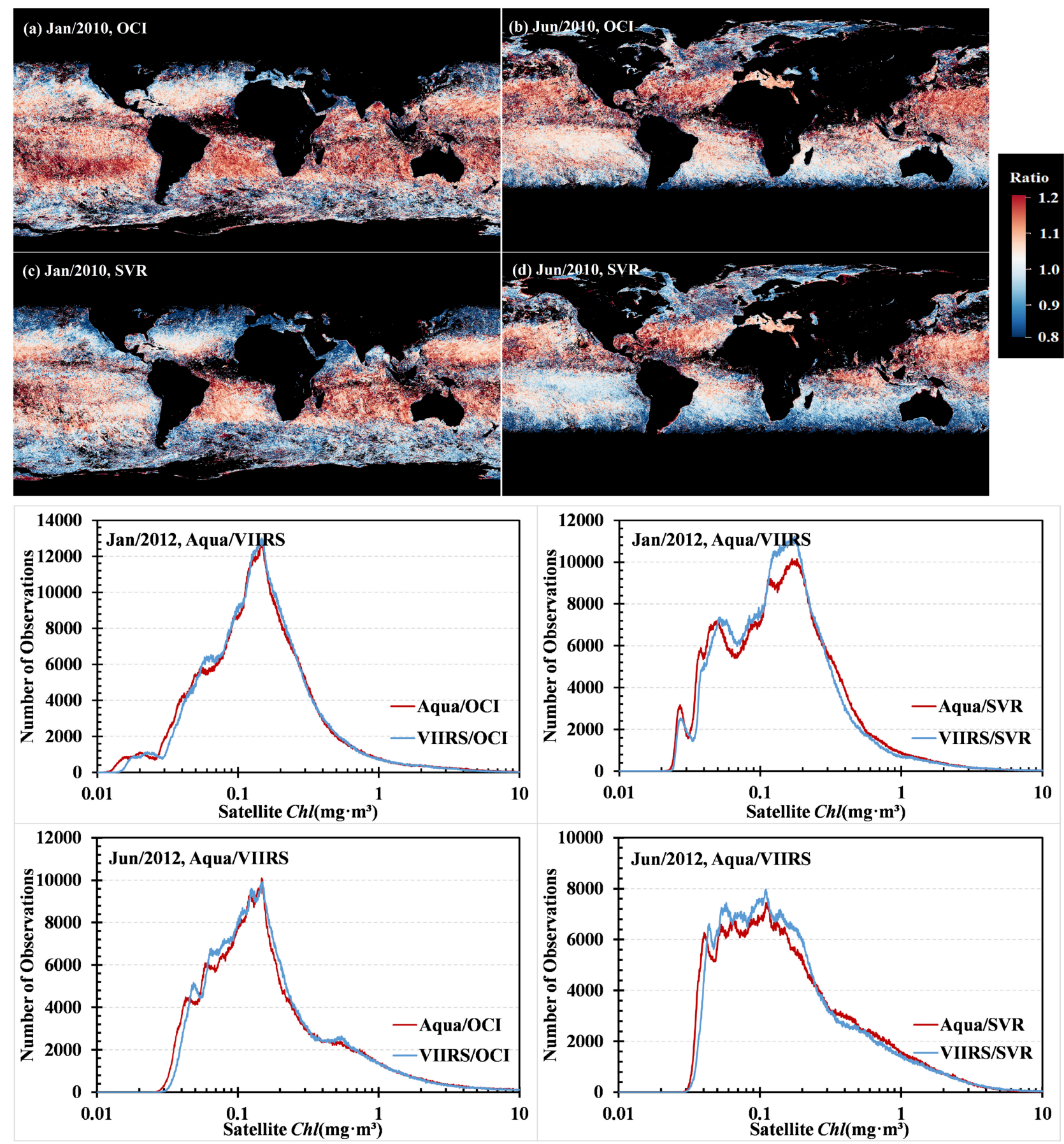

Fig. 13. Evaluation of cross-sensor consistency between VIIRS and MODISA using the OCI algorithm and SVR algorithm. (a) and (b) Ratio of MODISA/VIIRS OCI Chl for January and June 2010, respectively. (c) and (d) Ratio of MODISA/VIIRS SVR Chl for January and June 2010, respectively. A ratio of 1.0 indicates perfect consistency. The bottom panels show their histogram distributions. Chl data were derived from the $9-\mathrm{km}$ daily global $R_{\mathrm{rs}}$ data using the two algorithms.

\section{B. Algorithm Applicability}

Because SVR by nature is still an empirical algorithm, all pros and cons of empirical algorithms are applicable to the SVR algorithm developed here. Specifically, the algorithm is only applicable to the same data range and environmental conditions that were used in the algorithm training. In particular, unlike the band-ratio or band-subtraction algorithms ( $\mathrm{OC} x$ and $\mathrm{OCI}$ ) where the functional forms between $\mathrm{Chl}$ and $R_{\mathrm{rs}}$ are explicit and physically meaningful (e.g., blue-green band ratio increases with decreasing $\mathrm{Chl}$ in a monotonic way), the SVR algorithm does not have an explicit function form. Therefore, greater caution should be paid to regions where Chl values are either outside the training data range or collected under different conditions (e.g., under moderate sun glint), as these regions may show unexpected errors. This is also why in addition to field-based evaluations, image-based evaluations 
TABLE IV

Comparison of Algorithm Performance Between SVR (This Study) and the Most Recent Band-Ratio AlgorithmS (OC5 AND OC6 [12]) Using Concurrent SEAWiFS and SEABASS Data. Here, the OC5 and OC6 Algorithm Coefficients Are Applied to SeaWifs $R_{\text {rs }}$ Data to Estimate Chl

\begin{tabular}{|c|c|c|c|c|c|c|c|c|c|}
\hline & \multirow[b]{2}{*}{ SVR } & \multirow[b]{2}{*}{ OC5 } & \multirow[b]{2}{*}{ OC6 } & \multicolumn{3}{|c|}{ in-situ $\mathrm{Chl}<1 \mathrm{mg} / \mathrm{m}^{3}$} & \multicolumn{3}{|c|}{ in-situ $\mathrm{Chl}<0.25 \mathrm{mg} / \mathrm{m}^{3}$} \\
\hline & & & & SVR & OC5 & OC6 & SVR & OC5 & OC6 \\
\hline MAD & 1.57 & 1.62 & 1.63 & 1.51 & 1.58 & 1.58 & 1.53 & 1.60 & 1.62 \\
\hline Bias & 0.95 & 0.96 & 0.97 & 1.15 & 1.14 & 1.18 & 1.24 & 1.25 & 1.30 \\
\hline MRD & $51.9 \%$ & $59.6 \%$ & $57.5 \%$ & $59.2 \%$ & $69.7 \%$ & $67.5 \%$ & $75.2 \%$ & $92.9 \%$ & $87.6 \%$ \\
\hline RMSD & $173.7 \%$ & $292.8 \%$ & $189.9 \%$ & $211.8 \%$ & $360.0 \%$ & $232.1 \%$ & $299.7 \%$ & $515.9 \%$ & $328.1 \%$ \\
\hline UMRD & $42.1 \%$ & $44.3 \%$ & $44.7 \%$ & $39.2 \%$ & $42.6 \%$ & $43.1 \%$ & $39.5 \%$ & $43.3 \%$ & $44.5 \%$ \\
\hline URMSD & $54.2 \%$ & $56.9 \%$ & $56.9 \%$ & $50.0 \%$ & $53.6 \%$ & $54.0 \%$ & $52.0 \%$ & $55.3 \%$ & $57.1 \%$ \\
\hline Mean ratio & 1.17 & 1.25 & 1.2 & 1.38 & 1.46 & 1.46 & 1.58 & 1.74 & 1.70 \\
\hline Med ratio & 0.96 & 1.01 & 1.00 & 1.14 & 1.16 & 1.19 & 1.12 & 1.15 & 1.16 \\
\hline$R^{2}$ linear & 0.51 & 0.47 & 0.50 & 0.48 & 0.30 & 0.44 & 0.05 & 0.02 & 0.05 \\
\hline$R^{2} \log$ & 0.79 & 0.76 & 0.76 & 0.70 & 0.66 & 0.66 & 0.36 & 0.33 & 0.31 \\
\hline$N$ & 1145 & 1145 & 1145 & 748 & 748 & 748 & 357 & 357 & 357 \\
\hline
\end{tabular}

are performed here. To determine whether and where there might be data points from satellite measurements outside the algorithm training range, $R_{\mathrm{rs}}(\lambda)$ statistics from both SeaWiFS and MODISA measurements were analyzed in their spectral slopes and curvatures (Supplementary Figs. S4 and S5) and band ratios (Supplementary Figs. S6 and S7) for the SVR algorithm and OCx algorithm, respectively. The statistics were used to compare with the $R_{\mathrm{rs}}(\lambda)$ statistics used in the algorithm trainings (i.e., NOMAD data). Supplementary Fig. S4 shows that, for the SVR algorithm, there are indeed satellite data points outside the algorithm training range, and these data are mostly located in ocean gyres (extremely clear waters) with some scattered points near land (extremely turbid waters) (Supplementary Fig. S5). Likewise, Supplementary Fig. S6 shows that, for the OCx algorithm, there are also satellite data points outside the algorithm training range, and these data are also located in ocean gyres or near land (Supplementary Fig. S7).

Chl data statistics and histograms suggest that, for the clearest ocean gyres where Chl is $<\sim 0.02 \mathrm{mg} \mathrm{m}^{-3}$ (Supplementary Fig. S5), even though nearly no NOMAD data point used in the SVR training is in this Chl range, the SVR algorithm still yielded reasonable and consistent results among different sensors, suggesting that the SVR algorithm may be applicable to even the clearest waters in the ocean. For the same reason, the same can be said for the OCx algorithm (Supplementary Fig. S7).

On the other hand, field-based algorithm evaluations suggest that the SVR algorithm may yield negatively biased Chl for Chl $>1.0 \mathrm{mg} \mathrm{m}^{-3}$. This is possibly due to lack of sufficient data points in the algorithm training. Although there appear many data points in this range from the NOMAD data (see Fig. 1), they come from different coastal waters with different optical complexity (e.g., dominated by CDOM absorption or particle scattering), thus may not be sufficient to represent global coastal waters. This reason can also explain the relative large difference between SVR and OCI Chl in several marginal seas such as the Arabian Sea and the Sea of Okhotsk. Without sufficient field data to evaluate algorithm in these regions, it is currently difficult to verify which algorithm is better. However, considering that 1) $96 \%$ of the global oceans have $\mathrm{Chl}<1.0 \mathrm{mg} \mathrm{m}^{-3}$ according to SeaWiFS data statistics, 2) cross-sensor consistency is not affected by the negative bias, and 3) nearly all empirical algorithms for waters with $\mathrm{Chl}>1.0 \mathrm{mg} \mathrm{m}^{-3}$ require local algorithm tuning anyway (e.g., [29], [30], [55]-[59]), this shortcoming may not represent a significant drawback on the algorithm applicability. On the other hand, both empirical and semianalytical algorithms using the red and near infrared (NIR) bands have been developed to specifically target turbid coastal waters for Chl estimates [56]-[59], suggesting that for waters with Chl $>1 \mathrm{mg} \mathrm{m}^{-3}$ where the SVR algorithm performs poorly, localized approaches should be developed. Indeed, the improvement of algorithm performance from band-ratio OCx to SVR does not appear to be algorithm specific, but may be conceptual. For example, even after algorithm tuning using other bands, the most recent algorithm updates in the band-ratio approach [12] did not result in lower uncertainties than the SVR algorithm developed here. Tables IV and V show the comparison of algorithm performance between SVR and OC5 and OC6 using common SeaBASS and satellite data. The OC5 and OC6 Chl values were derived after applying the algorithms (together with their parameterization) to the satellite-derived $R_{\mathrm{rs}}(\lambda)$. It is clear that regardless of the data range (entire data set, $<1 \mathrm{mg} \mathrm{m}^{-3}$ or $<0.25 \mathrm{~m}^{-3}$ ), the SVR algorithm always shows the lowest data spread as measured by the MAD, MRD, UMRD, RMSD, and URMSD statistical measures. When measured by the mean ratio and median ratio, the results are mixed. Therefore, considering the additional advantage of the SVR approach in noise reduction, the SVR approach appears to be a feasible way to develop robust empirical algorithms to account for both known and unknown errors, and the current SVR Chl algorithm may serve as an alternative algorithm to the NASA's operational OCI algorithm.

The argument above is reinforced by applications of the SVR approach to other ocean color sensors, for example, MERIS. Results shown in Supplementary Figs. S8-S10 indicate that after appropriate training, the same SVR approach can successfully retrieve Chl over both global and local scales, 
TABLE V

Comparison of Algorithm Performance Between SVR (This Study) and the Most Recent Band-Ratio Algorithms (OC5 AND OC6 [12]) USIng CONCURRENT MODISA AND SEABASS Data. Here, THE OC5 AND OC6 Algorithm Coefficients Are Applied to MODis A $R_{\text {rs }}$ Data to Estimate ChL

\begin{tabular}{|c|c|c|c|c|c|c|c|c|c|}
\hline & \multirow[b]{2}{*}{ SVR } & \multirow[b]{2}{*}{ OC5 } & \multirow[b]{2}{*}{ OC6 } & \multicolumn{3}{|c|}{ in-situ $\mathrm{Chl}<1 \mathrm{mg} / \mathrm{m}^{3}$} & \multicolumn{3}{|c|}{ in-situ $\mathrm{Chl}<0.25 \mathrm{mg} / \mathrm{m}^{3}$} \\
\hline & & & & SVR & OC5 & OC6 & SVR & OC5 & OC6 \\
\hline MAD & 1.52 & 1.61 & 1.58 & 1.43 & 1.50 & 1.49 & 1.35 & 1.41 & 1.37 \\
\hline Bias & 0.98 & 0.91 & 0.95 & 1.23 & 1.16 & 1.20 & 1.19 & 1.12 & 1.14 \\
\hline MRD & $43.4 \%$ & $47.0 \%$ & $47.1 \%$ & $46.8 \%$ & $51.1 \%$ & $52.0 \%$ & $40.5 \%$ & $41.9 \%$ & $40.7 \%$ \\
\hline RMSD & $63.50 \%$ & $67.4 \%$ & $69.6 \%$ & $71.5 \%$ & $76.1 \%$ & $79.6 \%$ & $68.5 \%$ & $66.9 \%$ & $70.8 \%$ \\
\hline UMRD & $39.55 \%$ & $44.3 \%$ & $42.8 \%$ & $34.4 \%$ & $39.0 \%$ & $38.1 \%$ & $29.1 \%$ & $32.7 \%$ & $29.9 \%$ \\
\hline URMSD & $51.66 \%$ & $56.6 \%$ & $55.1 \%$ & $44.0 \%$ & $48.6 \%$ & $48.3 \%$ & $39.5 \%$ & $43.8 \%$ & $41.4 \%$ \\
\hline Mean ratio & 1.14 & 1.09 & 1.12 & 1.35 & 1.31 & 1.36 & 1.30 & 1.25 & 1.26 \\
\hline Med ratio & 1.04 & 0.98 & 0.99 & 1.20 & 1.14 & 1.18 & 1.11 & 1.09 & 1.06 \\
\hline$R^{2}$ linear & 0.40 & 0.46 & 0.52 & 0.57 & 0.47 & 0.49 & 0.52 & 0.53 & 0.50 \\
\hline$R^{2} \log$ & 0.78 & 0.74 & 0.75 & 0.75 & 0.76 & 0.77 & 0.71 & 0.72 & 0.71 \\
\hline$N$ & 331 & 331 & 331 & 212 & 212 & 212 & 63 & 63 & 63 \\
\hline
\end{tabular}

with algorithm performance slightly improved over the OCx band ratio algorithm, especially for $\mathrm{Chl}<1 \mathrm{mg} \mathrm{m}^{-3}$.

Finally, although SVR shows improved performance over OCx (for $\mathrm{Chl}<1.0 \mathrm{mg} \mathrm{m}^{-3}$ ) and OCI (for $\mathrm{Chl}$ between 0.25 and $1.0 \mathrm{mg} \mathrm{m}^{-3}$ ), and improved cross-sensor consistency over OCx, there are relatively large differences between the histogram distributions when the algorithm changes from OCI to SVR (see Figs. 12 and 13). Such differences will inevitably lead to changes in global $\mathrm{Chl}$ time-series analysis. Actually, there have been several rounds of global data reprocessing (https://oceancolor.gsfc.nasa.gov/reprocessing/), and each time an algorithm is changed (e.g., from the earlier OC2 to OC4, and then to the recent $\mathrm{OCI}$ ), global histograms and basin-wide averages are also changed. The question is which algorithm (OCx, OCI, and SVR) leads to more accurate results in time-series analysis and what are the implications on studies of climate variability when global processing switches from one algorithm to another. We feel that the question can be addressed with the following considerations.

One, statistics from field-data validations indicate that new algorithms are always more accurate than old ones (see tables and scatter plots in this article as well as in statistics from each historical reprocessing), otherwise there is no point to use the new algorithms. Two, statistically, it is nearly impossible to know which histogram distributions are closer to the "truth" because there is no way to collect field data even from an ocean basin (not to mention the global ocean) within a short period (e.g., one month). Three, however, it is possible to evaluate the algorithm performance in cross-sensor consistency. This is especially important for studies of climate variability because of the multiple sensors involved. This is why NASA adopted OCI as the default algorithm to bring all SeaWiFS, MODIS, and VIIRS to form a seamless multisensor data record (e.g., [60, Fig. 3.26]), even if OCI Chl histograms are different from OCx Chl histograms (see [14, Fig. 20]). In this regard, both OCI and SVR appear better than OCx, and they may both generate improved time-series for global-scale or basin-scale studies regardless of their differences in histogram distributions.

\section{Extension to Other Data Products}

The robustness of the SVR Chl algorithm suggests that it might be possible to extend the concept to other ocean color data products. As a test, we used the NOMAD data set to train an SVR algorithm to estimate the diffuse attenuation coefficient at $490 \mathrm{~nm}, K_{\mathrm{d}}(490)\left(\mathrm{m}^{-1}\right)$. While there are several forms of empirical and semianalytical algorithms proposed by the community [61]-[63], the current standard (or default) algorithm used by NASA to produce global $K_{\mathrm{d}}(490)$ data products is adopted from the blue-green band ratio algorithm [63] with algorithm coefficients tuned from the NOMAD data set. This algorithm is used here as the reference to evaluate the SVR algorithm.

Using the same methodology development approach as outlined in Section II-B, $R_{\mathrm{rs}}$ data from the NOMAD data set at the same four wavelengths $(443,490,555$, and $670 \mathrm{~nm})$ were used to train the SVR algorithm for $K_{\mathrm{d}}(490)$. The algorithm was then applied to satellite data, where colocated and concurrent field-measured $K_{\mathrm{d}}(490)$ from the SeaBASS data set were used to evaluate the algorithm performance.

Fig. 14 and Table VI show that for the entire $K_{\mathrm{d}}(490)$ range, the SVR $K_{\mathrm{d}}(490)$ algorithm yielded better performance than the band-ratio algorithm. The scatter plots show tighter relationships between SVR $K_{\mathrm{d}}(490)$ and in situ $K_{\mathrm{d}}(490)$ than between band-ratio $K_{\mathrm{d}}(490)$ and in situ $K_{\mathrm{d}}(490)$ for both SeaWiFS and MODISA. In particular, the significant overestimates in the band-ratio $K_{\mathrm{d}}(490)$ for $K_{\mathrm{d}}(490)>0.2 \mathrm{~m}^{-1}$ are much reduced. We attribute this improvement to the tolerance of the SVR algorithm to some unknown errors in the satellite-derived $R_{\mathrm{rs}}(\lambda)$.

Indeed, machine learning approaches have been demonstrated to be effective in estimating bio-optical properties from satellite measurements for regional studies. For example, a self-organizing neural network was developed to estimate sea surface $p \mathrm{CO}_{2}$ over the Atlantic subpolar gyre and North Atlantic, which performed much better than multiple linear regressions [64], [65]. Improved performance was also found in retrieval of IOPs for open oceans by using neural network [45]. Similarly, a neural network inversion algorithm 

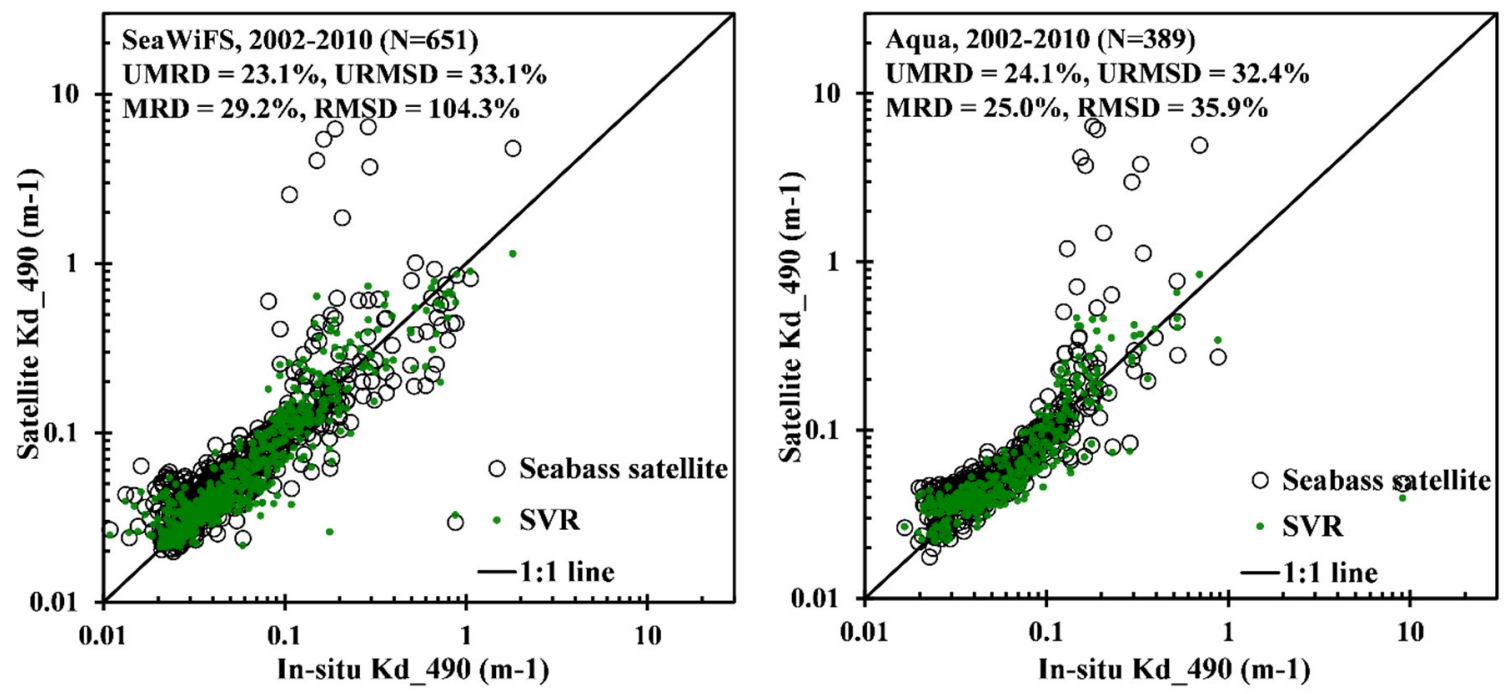

Fig. 14. Application of the SVR approach to estimate Kd_490 from (a) SeaWiFS and (b) MODISA. The approach was tuned using NOMAD2 data, and then applied to SeaWiFS and MODISA $R_{\mathrm{rs}}$ data from the SeaBASS archive to estimate Kd_490 (green dots). For comparison, the default SeaWiFS and MODISA Kd_490 data (empty circles) are also plotted.

TABLE VI

COMPARISON OF SEAWIFS- AND MODISA-DERIVEd KD_490 DATA USING Two AlgorithmS: THE NASA DEFAULt EMPIRICAL Algorithm ("DEFAUlT") AND THE SVR AlgORITHM DEVELOPED IN THIS STUdy ("SVR"). BOTH ALgORITHMS Were Applied to Satellite-Derived $R_{\text {rs }}$ And Evaluated Using In Situ Kd_490 Obtained From SeaBASS

\begin{tabular}{|c|c|c|c|c|c|c|c|c|c|c|c|c|}
\hline & & MAD & Bias & MRD & RMSD & UMRD & URMSD & $\begin{array}{l}\text { Mean } \\
\text { ratio }\end{array}$ & $\begin{array}{l}\text { Median } \\
\text { ratio }\end{array}$ & $\begin{array}{l}R^{2} \\
\text { linear }\end{array}$ & $R^{2} \log$ & $N$ \\
\hline \multirow[t]{2}{*}{ SeaWiFS } & Default & 1.35 & 1.13 & $59.5 \%$ & $276.5 \%$ & $27.6 \%$ & $40.8 \%$ & 1.45 & 1.06 & 0.28 & 0.80 & 651 \\
\hline & SVR & 1.27 & 1.00 & $29.2 \%$ & $104.3 \%$ & $23.1 \%$ & $33.1 \%$ & 1.10 & 0.98 & 0.89 & 0.87 & 651 \\
\hline \multirow[t]{2}{*}{ MODISA } & Default & 1.37 & 1.13 & $67.8 \%$ & $311.3 \%$ & $28.0 \%$ & $42.3 \%$ & 1.53 & 1.08 & 0.01 & 0.57 & 389 \\
\hline & SVR & 1.35 & 0.97 & $25.0 \%$ & $35.9 \%$ & $24.1 \%$ & $32.4 \%$ & 1.03 & 0.99 & 0.02 & 0.70 & 389 \\
\hline
\end{tabular}

was also developed to estimate $K_{\mathrm{d}}(490)$ for coastal and open water and compared it with other published algorithms, which had higher accuracy for derived $K_{\mathrm{d}}(490)$ than other algorithms [44]. Chen et al. [66] developed a neural net algorithm to estimate $K_{\mathrm{d}}(490)$ from MODISA measurements over the East China Sea and Yellow Sea, which showed improvements over the band-ratio algorithms. Chen et al. [67] developed an approach to use a RF-based regression ensemble (RFRE) to estimate sea surface $p \mathrm{CO}_{2}$ in the Gulf of Mexico and Gulf of Maine. Even if the explicit functional forms between sea surface $p \mathrm{CO}_{2}$ and MODIS-derived $R_{\mathrm{rs}}(\lambda)$ are unknown, the RFRE approach can successfully retrieve the former from the latter as long as there are sufficient field data to train the algorithm. Clearly, although caution is required when considering the applicability ranges, machine learning approaches may lead to robust algorithms to serve as alternatives of the current standard algorithms. For the same reason, although this study tested several popular machine learning approaches (e.g., GP, RF, MLP, and SVR) from which SVR was selected, there might be other machine learning approaches, after proper tuning and parameterization, that could yield equally well or even better performance than the SVR presented here. This is perhaps a subject of further research through more extensive tests in the future.
Finally, because of the lack of explicit functional expressions between $R_{\mathrm{rs}}$ and $\mathrm{Chl}$ in the SVR algorithm, it may be difficult for others to implement and test the algorithm for other sensors or for regional applications. To overcome this difficulty, the computer codes together with a README file are provided in the Supplementary Materials.

\section{CONCLUSiON}

A SVR algorithm has been developed from the NOMAD data set to estimate $\mathrm{Chl}$ in surface waters of the global oceans. Evaluation of its application to SeaWiFS, MODISA, and MERIS measurements shows improvements over the traditional band-ratio OC $x$ algorithms for the entire data range, and particularly for $\mathrm{Chl}<1 \mathrm{mg} \mathrm{m}^{-3}$. Although its performance is slightly worse than the band-subtraction OCI algorithm for Chl $<0.25 \mathrm{mg} \mathrm{m}^{-3}$, it avoids the algorithm transition from band subtraction to band ratio in the OCI algorithm design, thus assuring internal algorithm consistency for the entire range. Furthermore, the SVR algorithm is tolerant to image noise and artifacts, and its application to SeaWiFS, MODISA, and VIIRS leads to consistent results across different sensors. Application of the same approach also leads to similar improvements in the satellite-derived diffuse attenuation coefficient. Machine learning approaches may therefore serve as alternative ways 
to develop robust empirical algorithms for global oceans to estimate various bio-optical properties.

\section{ACKNOWLEDGMENT}

The authors thank all researchers who contributed to the NASA NOMAD data set and SeaBASS data archive. They are also grateful to the three anonymous reviewers who provided comments to help improve the presentation of this work. All satellite and field data were provided by the NASA OBPG through the NASA OB.DAAC (https://oceancolor.gsfc.nasa.gov).

\section{REFERENCES}

[1] C. Hu and J. Campbell, "Oceanic chlorophyll-a content," in Biophysical Applications of Satellite Remote Sensing. Cham, Switzerland: Springer, 2014, pp. 171-203.

[2] M. Wang, "Remote sensing of the ocean contributions from ultraviolet to near-infrared using the shortwave infrared bands: Simulations," Appl. Opt., vol. 46, no. 9, pp. 1535-1547, 2007.

[3] H. R. Gordon, "Atmospheric correction of ocean color imagery in the Earth Observing System era," J. Geophys. Res., Atmos., vol. 102, no. D14, pp. 17081-17106, Jul. 1997.

[4] H. R. Gordon and M. Wang, "Retrieval of water-leaving radiance and aerosol optical thickness over the oceans with SeaWiFS: A preliminary algorithm," Appl. Opt., vol. 33, pp. 443-452, Jan. 1994.

[5] R. C. Smith and K. S. Baker, "Oceanic chlorophyll concentrations as determined by satellite (Nimbus-7 coastal zone color Scanner)," Mar. Biol., vol. 66, no. 3, pp. 269-279, 1982.

[6] S. Tassan, "A global sensitivity analysis for the retrieval of chlorophyll concentrations from remote sensed radiances-the influence of wind," in Proc. Oceanogr. From Space, 1981, pp. 371-375.

[7] M. Viollier, D. Tanre, and P. Y. Deschamps, "An algorithm for remote sensing of water color from space," Boundary-Layer Meteorol., vol. 18, no. 3, pp. 247-267, May 1980.

[8] H. R. Gordon and D. K. Clark, "Atmospheric effects in the remote sensing of phytoplankton pigments," Boundary-Layer Meteorol., vol. 18, no. 3, pp. 299-313, May 1980.

[9] M. Viollier, P. Y. Deschamps, and P. Lecomte, "Airborne remote sensing of chlorophyll content under cloudy sky as applied to the tropical waters in the gulf of guinea," Remote Sens. Environ., vol. 7, no. 3, pp. 235-248, Aug. 1978.

[10] A. Morel and L. Prieur, "Analysis of variations in ocean color1," Limnology Oceanogr., vol. 22, no. 4, pp. 709-722, Jul. 1977.

[11] G. L. Clarke, G. C. Ewing, and C. J. Lorenzen, "Spectra of backscattered light from the sea obtained from aircraft as a measure of chlorophyll concentration," Science, vol. 167, no. 3921, pp. 1119-1121, Feb. 1970.

[12] J. E. O'Reilly and P. J. Werdell, "Chlorophyll algorithms for ocean color sensors-OC4, OC5 \& OC6," Remote Sens. Environ., vol. 229, pp. 32-47, Aug. 2019.

[13] C. Hu et al., "Improving satellite global chlorophyll a data products through algorithm refinement and data recovery," J. Geophys. Res., Oceans, vol. 124, no. 3, pp. 1524-1543, Mar. 2019.

[14] C. Hu, Z. Lee, and B. Franz, "Chlorophyll a algorithms for oligotrophic oceans: A novel approach based on three-band reflectance difference," J. Geophys. Res., Oceans, vol. 117, Jan. 2012, Art. no. C01011.

[15] J. E. O'Reilly et al., "Ocean color chlorophyll a algorithms for SeaWiFS, OC2, and OC4: Version 4," SeaWiFS Postlaunch Calibration, Validation Analyses, Part3, NASA Tech. Memorandum 2000-206892, 2000, vol. 11, pp. 9-23.

[16] M. J. Sauer, C. S. Roesler, P. J. Werdell, and A. Barnard, "Under the hood of satellite empirical chlorophyll a algorithms: Revealing the dependencies of maximum band ratio algorithms on inherent optical properties," Opt. Express, vol. 20, no. 19, pp. 20920-20933, 2012.

[17] M. Szeto, P. J. Werdell, T. S. Moore, and J. W. Campbell, "Are the world's oceans optically different?" J. Geophys. Res., vol. 116, p. C7, Oct. 2011

[18] H. M. Dierssen, "Perspectives on empirical approaches for ocean color remote sensing of chlorophyll in a changing climate," Proc. Nat. Acad. Sci. USA, vol. 107, no. 40, pp. 17073-17078, Oct. 2010.
[19] S. Sathyendranath, L. Prieur, and A. Morel, "A three-component model of ocean colour and its application to remote sensing of phytoplankton pigments in coastal waters," Int. J. Remote Sens., vol. 10, no. 8, pp. 1373-1394, Aug. 1989.

[20] K. L. Carder, F. R. Chen, Z. P. Lee, S. K. Hawes, and D. Kamykowski, "Semianalytic moderate-resolution imaging spectrometer algorithms for chlorophyll a and absorption with bio-optical domains based on nitratedepletion temperatures," J. Geophys. Res., Oceans, vol. 104, no. C3, pp. 5403-5421, Mar. 1999.

[21] F. E. Hoge and P. E. Lyon, "Satellite retrieval of inherent optical properties by linear matrix inversion of oceanic radiance models: An analysis of model and radiance measurement errors," J. Geophys. Res., Oceans, vol. 101, no. C7, pp. 16631-16648, Jul. 1996.

[22] C. S. Roesler and M. J. Perry, "In situ phytoplankton absorption, fluorescence emission, and particulate backscattering spectra determined from reflectance," J. Geophys. Res., Oceans, vol. 100, pp. 13279-13294, 1995.

[23] K. L. Carder, S. K. Hawes, K. A. Baker, R. C. Smith, R. G. Steward, and B. G. Mitchell, "Reflectance model for quantifying chlorophyll a in the presence of productivity degradation products," J. Geophys. Res., vol. 96, no. C11, pp. 20599-20611, Nov. 1991.

[24] W. Shi and M. Wang, "A blended inherent optical property algorithm for global satellite ocean color observations," Limnol. Oceanogr., Methods, vol. 17, no. 7, pp. 377-394, May 2019.

[25] S. Maritorena, D. A. Siegel, and A. R. Peterson, "Optimization of a semianalytical ocean color model for global-scale applications," Appl. Opt. vol. 41, no. 15, pp. 2705-2714, May 2002, doi: 10.1364/AO.41.002705.

[26] Z. Lee, K. Carder, and R. A. Arnone, "Deriving inherent optical properties from water color: A multiband quasi-analytical algorithm for optically deep waters," Appl. Opt., vol. 41, no. 27, pp. 5755-5772, 2002.

[27] Z. Lee, K. L. Carder, C. D. Mobley, R. G. Steward, and J. S. Patch, "Hyperspectral remote sensing for shallow waters: 2. Deriving bottom depths and water properties by optimization," Appl. Opt., vol. 38, no. 18, pp. 3831-3843, 1999.

[28] B. G. Mitchell and M. Kahru, "Bio-optical algorithms for ADEOS-2 GLI," J. Remote Sens. Soc. Jpn., vol. 29, no. 1, pp. 80-85, 2009.

[29] D. McKee, A. Cunningham, and A. Dudek, "Optical water type discrimination and tuning remote sensing band-ratio algorithms: Application to retrieval of chlorophyll and $\mathrm{Kd}(490)$ in the Irish and Celtic seas," Estuarine, Coastal Shelf Sci., vol. 73, nos. 3-4, pp. 827-834, Jul. 2007.

[30] M. Kahru and B. G. Mitchell, "Empirical chlorophyll algorithm and preliminary SeaWiFS validation for the California current," Int. J. Remote Sens., vol. 20, no. 17, pp. 3423-3429, Jan. 1999.

[31] J. E. O'Reilly et al., "Ocean color chlorophyll a algorithms for SeaWiFS, OC2, and OC4: Version 4," SeaWiFS Postlaunch Calibration Validation Analyses, Part, vol. 3, pp. 9-23, Jul. 2000.

[32] B. Dzwonkowski and X. H. Yan, "Development and application of a neural network based ocean colour algorithm in coastal waters," Int. J. Remote Sens., vol. 26, no. 6, pp. 1175-1200, Mar. 2005.

[33] H. Schiller and R. Doerffer, "Neural network for emulation of an inverse model operational derivation of case II water properties from MERIS data," Int. J. Remote Sens., vol. 20, no. 9, pp. 1735-1746, Jan. 1999.

[34] Q. Guan, L. Feng, X. Hou, G. Schurgers, Y. Zheng, and J. Tang, "Eutrophication changes in fifty large lakes on the Yangtze plain of China derived from MERIS and OLCI observations," Remote Sens. Environ., vol. 246, Sep. 2020, Art. no. 111890.

[35] T. Schroeder, I. Behnert, M. Schaale, J. Fischer, and R. Doerffer, "Atmospheric correction algorithm for MERIS above case-2 waters," Int. J. Remote Sens., vol. 28, no. 7, pp. 1469-1486, Apr. 2007.

[36] H. Zhan, P. Shi, and C. Chen, "Retrieval of oceanic chlorophyll concentration using support vector machines," IEEE Trans. Geosci. Remote Sens., vol. 41, no. 12, pp. 2947-2951, Dec. 2003.

[37] L. E. Keiner, "Estimating oceanic chlorophyll concentrations with neural networks," Int. J. Remote Sens., vol. 20, no. 1, pp. 189-194, Jan. 1999.

[38] L. Gross, S. Thiria, R. Frouin, and B. G. Mitchell, "Artificial neural networks for modeling the transfer function between marine reflectance and phytoplankton pigment concentration," J. Geophys. Res., Oceans, vol. 105, no. C2, pp. 3483-3495, Feb. 2000.

[39] A. Tanaka, M. Kishino, R. Doerffer, H. Schiller, T. Oishi, and T. Kubota, "Development of a neural network algorithm for retrieving concentrations of chlorophyll, suspended matter and yellow substance from radiance data of the ocean color and temperature scanner," J. Oceanogr., vol. 60, no. 3, pp. 519-530, 2004.

[40] T. Zhang, "Evaluating the performance of artificial neural network techniques for pigment retrieval from ocean color in case I waters," J. Geophys. Res., vol. 108, no. C9, p. 3286, 2003. 
[41] Y. Zhang, S. S. Koponen, J. T. Pulliainen, and M. T. Hallikainen, "Application of empirical neural networks to chlorophyll—A estimation in coastal waters using remote optosensors," IEEE Sensors J., vol. 3 , no. 4, pp. 376-382, Aug. 2003.

[42] D. D'Alimonte and G. Zibordi, "Phytoplankton determination in an optically complex coastal region using a multilayer perceptron neural network," IEEE Trans. Geosci. Remote Sens., vol. 41, no. 12, pp. 2861-2868, Dec. 2003.

[43] H. Loisel, D. Stramski, D. Dessailly, C. Jamet, L. Li, and R. A. Reynolds, "An inverse model for estimating the optical absorption and backscattering coefficients of seawater from remote-sensing reflectance over a broad range of oceanic and coastal marine environments," J. Geophys. Res., Oceans, vol. 123, no. 3, pp. 2141-2171, Mar. 2018

[44] C. Jamet, H. Loisel, and D. Dessailly, "Retrieval of the spectral diffuse attenuation coefficient $\mathrm{K}_{d}(\lambda)$ in open and coastal ocean waters using a neural network inversion," J. Geophys. Res., Oceans, vol. 117, Oct. 2012, Art. no. C10023.

[45] I. Ioannou, A. Gilerson, B. Gross, F. Moshary, and S. Ahmed, "Neural network approach to retrieve the inherent optical properties of the ocean from observations of MODIS," Appl. Opt., vol. 50, no. 19, pp. 3168-3186, 2011.

[46] P. J. Werdell and S. W. Bailey, "An improved in-situ bio-optical data set for ocean color algorithm development and satellite data product validation," Remote Sens. Environ., vol. 98, no. 1, pp. 122-140, Sep. 2005.

[47] J. W. Campbell, "The lognormal distribution as a model for bio-optical variability in the sea," J. Geophys. Res., vol. 100, no. C7, p. 13237, 1995.

[48] P. J. Werdell et al., "Unique data repository facilitates ocean color satellite validation," Eos, vol. 84, no. 38, pp. 377-387, 2003.

[49] S. W. Bailey and P. J. Werdell, "A multi-sensor approach for the on-orbit validation of ocean color satellite data products," Remote Sens. Environ., vol. 102, nos. 1-2, pp. 12-23, May 2006.

[50] H. Chuanmin, L. Zhongping, and B. Franz, "Minimize CDOM impact on the bandsubtraction chlorophyll algorithm through optical weighting: Preliminary results," in Proc. 22nd Ocean Opt., Portland, ME, USA, Oct. 2014

[51] C. Hu et al., "Dynamic range and sensitivity requirements of satellite ocean color sensors: Learning from the past," Appl. Opt., vol. 51, no. 25 , pp. 6045-6062, 2012.

[52] M. J. Behrenfeld et al., "Satellite-detected fluorescence reveals global physiology of ocean phytoplankton," Biogeosciences, vol. 6, no. 5, pp. 779-794, May 2009.

[53] C. Hu et al., "Red tide detection and tracing using MODIS fluorescence data: A regional example in SW florida coastal waters," Remote Sens. Environ., vol. 97, no. 3, pp. 311-321, Aug. 2005.

[54] L. Feng and C. Hu, "Comparison of valid ocean observations between MODIS Terra and Aqua over the global oceans," IEEE Trans. Geosci. Remote Sens., vol. 54, no. 3, pp. 1575-1585, Mar. 2016.

[55] J. P. Cannizzaro et al., "On the accuracy of SeaWiFS ocean color data products on the West Florida Shelf," J. Coastal Res., vol. 29, no. 6, pp. 1257-1272, 2013 .

[56] G. Zheng and P. M. DiGiacomo, "Remote sensing of chlorophyll-a in coastal waters based on the light absorption coefficient of phytoplankton," Remote Sens. Environ., vol. 201, pp. 331-341, Nov. 2017.

[57] C. Le, C. Hu, J. Cannizzaro, D. English, F. Müller-Karger, and Z. Lee, "Evaluation of chlorophyll-a remote sensing algorithms for an optically complex estuary," Remote Sens. Environ., vol. 129, pp. 75-89, Feb. 2013.

[58] A. A. Gitelson et al., "A simple semi-analytical model for remote estimation of chlorophyll-a in turbid waters: Validation," Remote Sens. Environ., vol. 112, no. 9, pp. 3582-3593, Sep. 2008.

[59] G. Dall'Olmo, A. A. Gitelson, D. C. Rundquist, B. Leavitt, T. Barrow, and J. C. Holz, "Assessing the potential of SeaWiFS and MODIS for estimating chlorophyll concentration in turbid productive waters using red and near-infrared bands," Remote Sens. Environ., vol. 96, no. 2 , pp. 176-187, May 2005.

[60] J. Blunden and D. S. Arndt, "State of the climate in 2016," Bull. Amer Meteorological Soc., vol. 98, no. 8, p. Si-280, 2016.

[61] A. Morel, Y. Huot, B. Gentili, P. J. Werdell, S. B. Hooker, and B. A. Franz, "Examining the consistency of products derived from various ocean color sensors in open ocean (Case 1) waters in the perspective of a multi-sensor approach," Remote Sens. Environ., vol. 111, no. 1, pp. 69-88, Nov. 2007.

[62] Z.-P. Lee, "A model for the diffuse attenuation coefficient of downwelling irradiance," J. Geophys. Res., vol. 110, 2005, Art. no. C02016.
[63] J. L. Mueller, "SeaWiFS algorithm for the diffuse attenuation coefficient, K (490), using water-leaving radiances at 490 and $555 \mathrm{~nm}$," SeaWiFS Postlaunch Calibration Validation Analyses, Part, vol. 3, no. 11, pp. 24-27, 2000.

[64] N. Lefevre, A. J. Watson, and A. R. Watson, "A comparison of multiple regression and neural network techniques for mapping in situ $\mathrm{pCO}_{2}$ data," Tellus B, vol. 57, no. 5, pp. 375-384, Nov. 2005.

[65] M. Telszewski et al., "Estimating the monthly $p \mathrm{CO}_{2}$ distribution in the North Atlantic using a self-organizing neural network," Biogeosciences, vol. 6, no. 8, pp. 1405-1421, 2009.

[66] J. Chen, T. Cui, J. Ishizaka, and C. Lin, "A neural network model for remote sensing of diffuse attenuation coefficient in global oceanic and coastal waters: Exemplifying the applicability of the model to the coastal regions in eastern China seas," Remote Sens. Environ., vol. 148, pp. 168-177, May 2014.

[67] S. Chen, C. Hu, B. B. Barnes, Y. Xie, G. Lin, and Z. Qiu, "Improving ocean color data coverage through machine learning," Remote Sens. Environ., vol. 222, pp. 286-302, Mar. 2019.

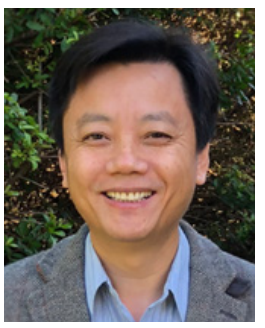

Chuanmin $\mathrm{Hu}$ received the B.Sc. degree in physics from the University of Science and Technology of China, Hefei, China, in 1989, and the Ph.D. degree in physics from the University of Miami, Coral Gables, FL, USA, in 1997.

From 2009 to 2014, he was a Topical Editor on ocean optics and ocean color remote sensing at the Applied Optics. From 2015 to 2017, he was a Chief Editor at the Remote Sensing of Environment. $\mathrm{He}$ is a Professor of optical oceanography with the University of South Florida, Tampa, FL, USA, where he also directs Optical Oceanography Laboratory. He uses laboratory, field, and remote sensing techniques to study marine algal blooms (harmful and nonharmful, macroalgae, and microalgae), oil spills, coastal and inland water quality, and global changes.

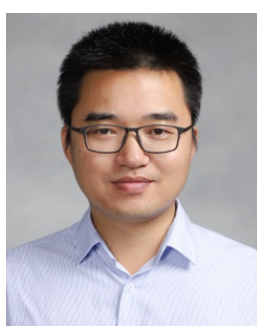

Lian Feng received the Ph.D. degree from Wuhan University, Wuhan, China, in 2013.

From 2015 to 2017, he was a Post-Doctoral Researcher with the University of South Florida, Tampa, FL, USA. He is an Assistant Professor with the School of Environmental Science and Engineering, Southern University of Science and Technology, Shenzhen, China. His research interests include remote sensing of inland and coastal water environments and how these environments are influenced by climate variability and human activities.

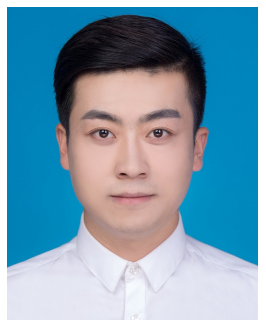

Qi Guan received the master's degree from Wuhan University, Wuhan, China, in 2019. He is pursuing the Ph.D. degree with the School of Environmental Science and Engineering, Southern University of Science and Technology, Shenzhen, China, and with the Department of Geoscience and Natural Resource Management, University of Copenhagen, Copenhagen, Denmark.

His research interests include remote sensing of water environments and how these environments are affected by carbon and nitrogen cycling of ecosystems. 